\title{
A wearable piezo-resistive sensor for capturing cardiorespiratory signals
}

DOI:

10.1016/j.sna.2018.09.015

\section{Document Version}

Accepted author manuscript

Link to publication record in Manchester Research Explorer

\section{Citation for published version (APA):}

Wang, Y., Ali, S., Gong, R., Wijekoon, J., \& Fernando, A. (2018). A wearable piezo-resistive sensor for capturing cardiorespiratory signals. Sensors and Actuators, A: Physical, 282, 215-229.

https://doi.org/10.1016/j.sna.2018.09.015

\section{Published in:}

Sensors and Actuators, A: Physical

\section{Citing this paper}

Please note that where the full-text provided on Manchester Research Explorer is the Author Accepted Manuscript or Proof version this may differ from the final Published version. If citing, it is advised that you check and use the publisher's definitive version.

\section{General rights}

Copyright and moral rights for the publications made accessible in the Research Explorer are retained by the authors and/or other copyright owners and it is a condition of accessing publications that users recognise and abide by the legal requirements associated with these rights.

\section{Takedown policy}

If you believe that this document breaches copyright please refer to the University of Manchester's Takedown Procedures [http://man.ac.uk/04Y6Bo] or contact uml.scholarlycommunications@manchester.ac.uk providing relevant details, so we can investigate your claim.

\section{OPEN ACCESS}




\title{
A wearable piezo-resistive sensor for capturing cardiorespiratory signals
}

\author{
Yuhua Wang ${ }^{\mathrm{a}, *}$, Sammia Ali ${ }^{\mathrm{a}}$, Jayawan Wijekoon ${ }^{\mathrm{b}}$, R Hugh Gong ${ }^{\mathrm{a}}$, \\ Anura Fernando ${ }^{\text {a }}$ \\ ${ }^{a}$ School of Materials, University of Manchester, UK \\ ${ }^{\mathrm{b}}$ School of Electrical \& Electronic Engineering, University of Manchester, UK \\ * Corresponding author: \\ E-mail: yuhua_wang@outlook.com (Yuhua Wang)
}

\begin{abstract}
This paper presents the performance of a new nonwoven piezo-resistive sensor for capturing cardiorespiratory signals. The novel piezo-resistive sensor is fabricated by sandwiching a nano silver electro-conductive ink impregnated nonwoven material between two layers of knitted silver fabric that function as sensor electrodes. The paper describes the technology for minimizing the signal noise due to motion artifacts in the sensor. The nonwoven piezo-resistive sensor is tested on volunteers by capturing their cardiorespiratory signals, where the signal noise is filtered using a bandpass filter. The paper further presents the analysis of the performance of the sensor together with a comparison against a commercially available, portable, cardiorespiratory signal monitoring device. The study shows that the wearable nonwoven piezo-resistive sensor system is highly sensitive, and it is an accurate and reliable sensor for capturing cardiorespiratory signals.
\end{abstract}

\section{Keywords}

Nano silver ink, piezo-resistive, smart textile, pressure sensor, nonwoven

\section{Introduction}

Due to the increased pace of modern life where higher pressures from work are experienced, more and more people have been found to suffer from issues related to mental/physical stress. Heart disease is one such medical condition that could be caused from mental stress [1]. Reports show instances where individuals with such heart conditions were found suffering from severe mental stress or sometimes found unconscious [2-4]. In order to manage such situations or medical conditions, one method is to carry out long-term cardiorespiratory monitoring on those with high heart disease risk. Therefore wearable cardiorespiratory sensing systems can play a critical role in ambulatory monitoring.

Increasingly electro-textiles are becoming one of the most popular sensory materials used in wearable sensors due to their structural \& mechanical properties and their readiness to be the scaffold for carrying electronic sensors and control units [5-7]. The ability to replace the electronic power and data transmission lines in wearable systems with electroconductive textile materials gives them an advantage over bulky solid electronic components. Additionally, the availability of assistive technologies for garment manufacturing (3D body scanning, scan to knit garment design \& manufacturing and the CAD based embroidery methods for the integration of sensor/ actuator systems and 
power/ data transmission networks onto wearable biosensing systems) make electrotextiles a highly suitable material for wearable electronic devices.

Nonwoven electro-textile materials are one of the unique electro-textile materials that are in use as a textile sensory material. The fine fibers and the fiber mesh structure of the nonwoven materials make them superb piezo-resistive sensors that are responsive to low stresses, strains, and vibrations [8], especially for capturing cardiorespiratory signals. The electro-conductive materials can be distributed evenly throughout the nonwoven materials due to the random fibrous structure [8]. Compared to other wearable sensors such as capacitive sensors, the piezo-resistive nonwoven sensors are less prone to interference from electromagnetic noise and motion artifacts [9]. In the last few years, records show instances where nonwoven fabric based electro-textile wearable sensors were developed and employed in commercial applications [10]; in one such example, nonwoven carrier fabric coated with carbon nanotubes were created to form an electroconductive strain sensor [11]. Another research describes where a ferroelectric strain sensor was developed based on a nonwoven fabric produced from polyvinylidene fluoride (PVDF) $[12,13]$. These are some of the numerous examples available.

Out of the vast range of electro-conductive inks, silver (Ag) based electro-conductive inks are popular among the smart/electro-textile research community. The reasons for this are their better performance to cost ratios exhibited by silver based electro-conductive inks and the low electrical resistivity of silver, which is around $15.87 \mathrm{n} \Omega \cdot \mathrm{m}$ [14], making this material one of the best candidates in the field of electro-conductive inks. Silver micro/nanoparticles, which are the primary materials used in these electro-conductive inks, can be relatively easily synthesized using chemical methods, such as dissolving a silver salt into an organic solvent [15]. As research shows, the presence of agglomerates makes silver ink based electro-textiles inconsistent in its properties [16,17]. To obtain an agglomerate-free, highly dispersed silver solution, it is necessary to moderate their coagulation during the synthesis process, by adding a protective coating on the silver [18-21]. This method produces silver particle ink with a particle size ranging from 50 to $100 \mathrm{~nm}$ at a silver content of 49\% [20]. As observed during the research, adding an appropriate amount of a suitable acrylic resin in the process could solve the problem of the formation of agglomerates. However, this particle dispersion is achieved by sacrificing the low resistivity of the silver ink [22]. Current research has adopted the innovative silver ink synthesis method (using silver acetate $\left(\mathrm{NH}_{4} \mathrm{OH} / \mathrm{H}_{2} \mathrm{O}+\right.$ $\left.\mathrm{AgC}_{2} \mathrm{H}_{3} \mathrm{O}_{2}+\mathrm{CH}_{2} \mathrm{O}_{2} \rightarrow\left[\mathrm{Ag}\left(\mathrm{NH}_{3}\right)\right]^{+}\left[\mathrm{C}_{2} \mathrm{H}_{3} \mathrm{O}_{2}\right]^{-} \rightarrow \mathrm{Ag}\right)$ ) described by Walker and Lewis [23].

In order to ensure the correct bonding of the silver particles to the textile substrate and the enhancement of the electro-conductivity of the resulting electro-textile, the ink requires sintering. As literature states, in using a thermal sintering process, the sintering temperature below $100^{\circ} \mathrm{C}$ will cause the treatment to be incomplete, consequently leading to a reduced conductivity value [24]. The sintered silver ink might have a hairy fuzzy appearance if the silver content is low; however, this can be overcome by raising the sintering temperature to $250^{\circ} \mathrm{C}$ [25]. Plasma and laser energy is another approach that can also be used in the sintering process of silver inks [26-29]. Another sintering method called solution soaking treatment can be applied to sinter silver particles on paper or plastic substrates [30]. Fast sintering at lower sintering temperatures can be achieved by a 
sintering method based on temperature-sensitive photo paper [31]. Microwave sintering is also a useful approach for the creation of conductive silver deposition on a polymerbased substrate [32-34].

As the title of this paper describes, the current research aims to present the work carried out and the evaluation of an electro-conductive, nonwoven fabric based piezo-resistive sensor that can be used for capturing the heart and the breathing signals of an individual. The paper further presents the advantage of using webbing fabrics (to improve the stability of the sensor) and nonwoven materials with modified surface properties to optimize the performance of the sensor.

\section{Methodology}

In a piezo-resistive nonwoven pressure sensor, on the application of mechanical pressure, the thickness of the material will reduce and will cause the electro-conductive particles to move closer. This, in turn, reduces the electrical resistance of the material. The change in the electrical resistance on the application of mechanical pressure defines the working principle of a nonwoven piezo-resistive pressure sensor, as illustrated in Figure 1.

\section{Un-impregnated nonwoven fabric}

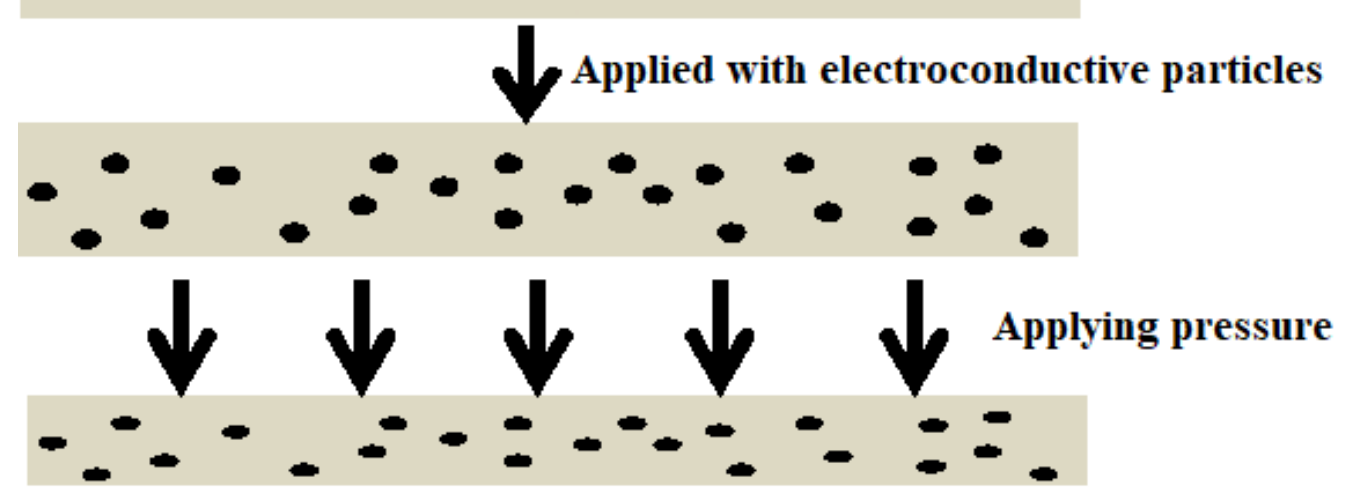

Figure 1. A schematic diagram of the operational principle of the nonwoven fabric based piezo-resistive material.

The nonwoven compressive piezo-resistive sensor consists of a core layer of nano silver electro-conductive ink impregnated nonwoven fabric that exhibits piezo-resistive properties. In wearable electronic devices, this piezo-resistivity is used to detect and capture weak Ballistocardiogram (BCG) and breathing signals. In order to construct the piezo-resistive sensor, this core nonwoven layer is then sandwiched between two layers of silver knitted electrodes. The complete assembly is reinforced by thermally bonding the silver knitted electrode layers and the piezo-resistive layer using webbing fabrics.

In this research, the nonwoven sensors were classified into two types: smooth surface pattern nonwoven sensor and embossed dotted pattern nonwoven sensor. The paper presents the investigation carried out to find out the effectiveness of the webbing fabrics in stabilizing the relative movements between the material layers in the nonwoven piezoresistive sensor, while maintaining an overall low sensor electrical resistance and high piezo-resistive sensitivity. 
Additionally, the paper presents the in-depth work carried out to capture a subject's breathing signal and heartbeat signal, during a test period, including normal breathing, rapid breathing, breath holding and body movement. These test results were compared with a commercially available bio-signal sensing device to verify the performance of the nonwoven piezo-resistive sensor. The paper further extends this investigation to a group of volunteers to evaluate the reliability of the sensor.

\section{Experimental Section}

\subsection{Preparation and characterization of silver nano particle ink}

In order to make the nano silver ink, $5 \mathrm{~g}$ of silver acetate $(\geq 99.0 \%$, powder, from Sigma Aldrich) was dissolved in $12.5 \mathrm{ml}$ of ammonia solution (33\%, liquid, ammonium hydroxide, from Sigma Aldrich) and stirred, until the solution became completely transparent and clear. Then, $1 \mathrm{ml}$ of formic acid ( $\geq 98 \%$, liquid, from Sigma Aldrich) was added into the solution as droplets. The solution, together with the black pre-matured silver salt agglomerates that formed, was capped for 24 hours. After the 24 hours standing period, the clear solution was transferred into a syringe filter with a pore size of $0.2 \mu \mathrm{m}$ for filtering. The filtered solution, with a silver content of $65 \mathrm{mg} / \mathrm{ml}$, was used as the nano silver conductive ink in the later impregnation process.

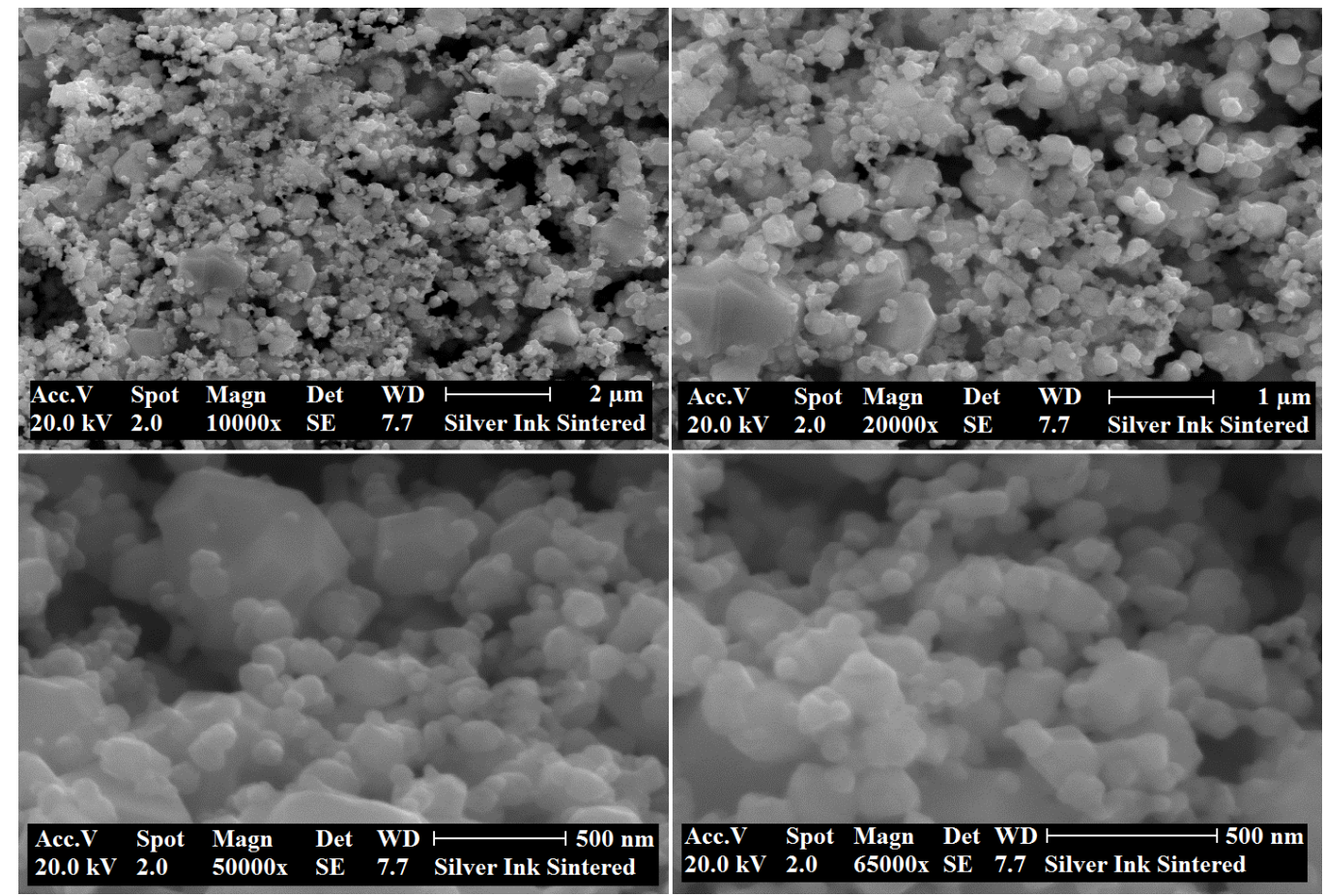

Figure 2. The SEM images of the sintered nano silver conductive ink under 10000x, 20000x, 50000x and 65000x magnifications.

It can be seen in Figure 2 that the thermally sintered nano silver ink shows spherical silver particles, which are independent of each other. The diameter of most of the silver particles is less than $130 \mathrm{~nm}$. However, it is noticeable that some large crystallizations are also present. The average diameter of the silver particles is $123 \mathrm{~nm}$, averaging from 100 measurements, with a standard error of $3.07 \mathrm{~nm}$. Figure 3 and Table 1 show the results 
of the EDX elemental spectrum. It can be found that the sintered nano silver particle ink has a silver content of $97.96 \%$.

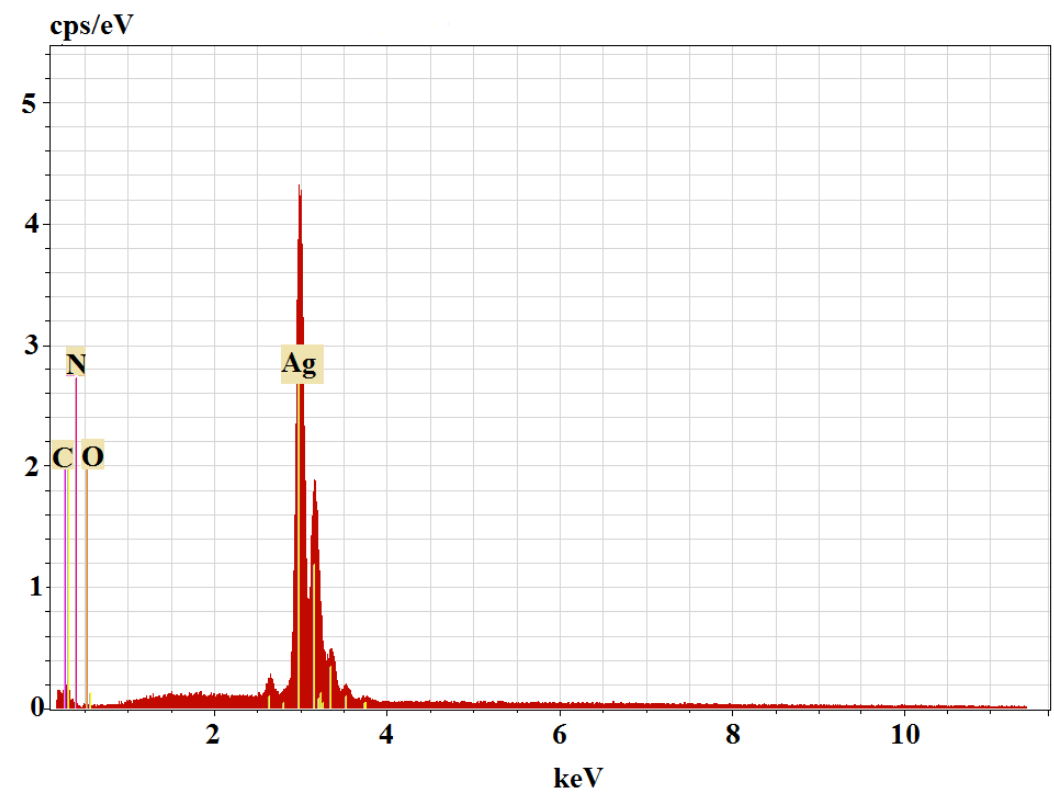

Figure 3. The EDX spectrum of the sintered nano silver ink.

Table 1. The weight percentages of silver, nitrogen, carbon and oxygen elements in the sintered nano silver ink.

\begin{tabular}{lll}
\hline Element & Atomic number & Normalized weight (\%) \\
\hline Silver & 47 & 97.96 \\
Nitrogen & 7 & 1.07 \\
Carbon & 6 & 0.64 \\
Oxygen & 8 & 0.33 \\
Sum & - & 100 \\
\hline
\end{tabular}

\subsection{Silver nano particle impregnation of nonwoven fabrics}

In applying this nano silver ink to the nonwoven fabrics, it is obvious that dilution of the ink would result in lower electrical conductivity in the sensor. Therefore, the nano silver ink produced through the above mentioned process was used without dilution in manufacturing the sensor fabrics.

A nonwoven fabric of $45 \mathrm{~mm}$ by $45 \mathrm{~mm}$ was immersed in $4 \mathrm{ml}$ of the nano silver particle ink prepared by the method mentioned in 3.1 for five minutes. In order to remove the excess nano silver ink, the dip coated nonwoven fabric was then run through the mangle machine (Werner Mathis CH-8155 Pad Mangle) once, at the mangle speed of $1.5 \mathrm{~m} / \mathrm{min}$ 
and the pressure value of 1 bar. Then the nonwoven fabric was thermally sintered at 120 ${ }^{\circ} \mathrm{C}$ for 30 minutes to improve the electrical conductivity.

Since impregnating the nonwoven fabrics at a higher mangling pressure would result in a lower amount of nano silver particles in the nonwoven fabric (reducing the sensor electrical conductivity), the mangling pressure during the impregnation process was held at the lowest possible setting of 1 bar.

The details and photos of the piezo-resistive nonwoven fabrics produced by the method mentioned above are summarized in Table 2 and Figure 4.

Table 2. Details of the nonwoven sensor fabrics.

\begin{tabular}{lllllll}
\hline Fabric name & $\begin{array}{l}\text { Thickness } \\
(\mathrm{mm})\end{array}$ & $\begin{array}{l}\text { Area } \\
\text { density } \\
\left(\mathrm{g} / \mathrm{m}^{2}\right)\end{array}$ & Fiber type & Source & $\begin{array}{l}\text { Silver take-up } \\
(\%)\end{array}$ & Sensor \\
\hline $\begin{array}{l}\text { Embossed } \\
\text { dotted } \\
\text { pattern } \\
\text { nonwoven }\end{array}$ & 0.61 & 60 & & 30 & $\mathrm{~A}$ \\
$\begin{array}{l}\text { Smooth } \\
\text { pattern } \\
\text { nonwoven }\end{array}$ & 0.65 & 80 & $\begin{array}{l}\text { Polypropylene } \\
\text { /Polyester } \\
\text { Blend ratio } 1: 1\end{array}$ & Lantor & & \\
\hline
\end{tabular}

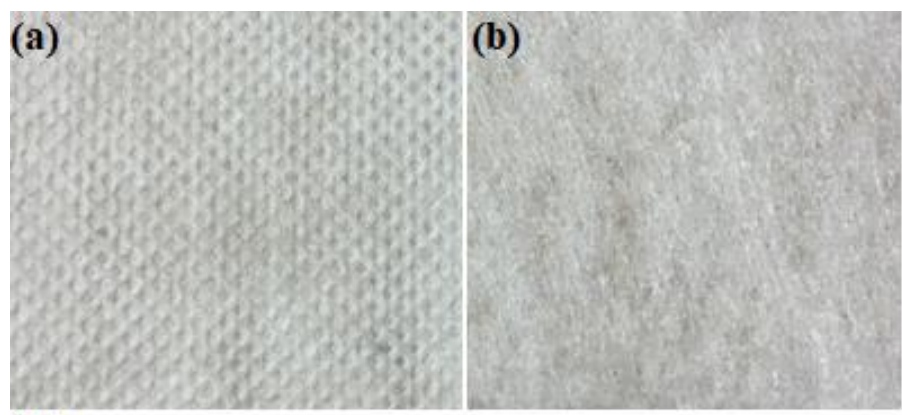

(c)

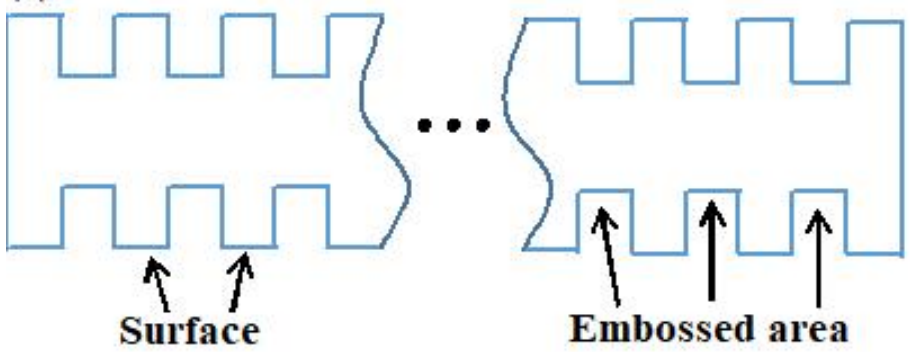

Figure 4. Photos of (a) dot embossed nonwoven fabric and (b) smooth surface nonwoven. (c): a schematic of dot embossed nonwoven fabric.

Two types of nonwoven materials with different surface structures were made with the same fiber materials of similar thickness. The embossed dotted pattern nonwoven fabrics had lower area density, due to the fact that they were partially bonded in order to create the unique surface structure, therefore, resulting in a lower silver take-up percentage than 
the smooth pattern nonwoven fabric. The silver content take-up $(T)$ was calculated using the following equation:

$$
T=\frac{W-W_{0}}{W_{0}} \times 100 \%
$$

where: $W$ is the weight of the impregnated nonwoven fabric after mangling and thermal sintering; $W_{0}$ is the weight of the unimpregnated nonwoven fabric.

\subsection{Sensor design and fabrication}

Table 3 lists the functional fabrics used in the fabrication of the piezo-resistive nonwoven sensors. The silver knitted fabrics (MedTex P-130) were used as electrodes that connected the piezo-resistive nonwoven sensor to a circuit for the measurement of electrical resistance. The silver knitted fabrics had very low electrical resistance $(<100$

Ohms $/ \mathrm{m}^{2}$ ) which could be considered as a conductor during testing. The webbing fabrics acted as adhesives to improve the connections between nonwoven fabrics and electrode fabrics.

Table 3. The functional fabrics.

\begin{tabular}{|c|c|c|c|c|c|}
\hline Fabric name & $\begin{array}{l}\text { Thickness } \\
(\mathrm{mm})\end{array}$ & Function & $\begin{array}{l}\text { Area density } \\
\left(\mathrm{g} / \mathrm{m}^{2}\right)\end{array}$ & Properties & Source \\
\hline $\begin{array}{l}\text { Silver knitted } \\
\text { fabric } \\
\text { (MedTex P-130) }\end{array}$ & 0.38 & Electrode & 140 & $\begin{array}{l}\text { Silver coated nylon yarn } \\
\text { Surface electrical resistance: } \\
<100 \Omega / \mathrm{m}^{2}\end{array}$ & $\begin{array}{l}\text { HITEK } \\
\text { LTD. }\end{array}$ \\
\hline Webbing fabric & 0.13 & $\begin{array}{l}\text { Adhesive } \\
\text { material }\end{array}$ & 19 & $\begin{array}{l}\text { Low density polyethylene } \\
\text { (LDPE) } \\
\text { Melting temperature: } \\
60{ }^{\circ} \mathrm{C}\end{array}$ & \\
\hline
\end{tabular}

The sensor was fabricated by sandwiching a piezo-resistive nonwoven fabric (size $45 \mathrm{~mm}$ by $45 \mathrm{~mm}$ ) between two layers of silver knitted fabric (size $40 \mathrm{~mm}$ by $40 \mathrm{~mm}$ ) and webbing fabric (size $40 \mathrm{~mm}$ by $40 \mathrm{~mm}$ ). The size of the nonwoven fabric layer was larger than those of silver knitted fabric and webbing fabric, in order to prevent any electrical short-circuiting between silver knitted fabric layers. After properly aligning the each of the layers, a clothes iron was used to apply a heat level of $60^{\circ} \mathrm{C}$, in order to melt the webbing fabric layer to provide adhesion. It was observed, the webbing fabric only provided sufficient surface adhesion to the nonwoven layer and silver knitted electrode layer, without any modifications to the inner fabric structures of the nonwoven or electrode fabric materials. The webbing fabrics were also impregnated with the nano silver ink in order to improve the electrical conductivity. However, due to the low melting temperature of the webbing fabric, the sintering process of the impregnated webbing fabrics was carried out at $45{ }^{\circ} \mathrm{C}$ for 1 hour. Since the silver impregnated webbing fabric was melted in order to bond the silver knitted electrode layer and the piezo-resistive nonwoven fabric, the silver impregnated webbing fabric does not function 
as a piezo-resistive material. The layer arrangement of the sensor design is demonstrated in Figure 5.

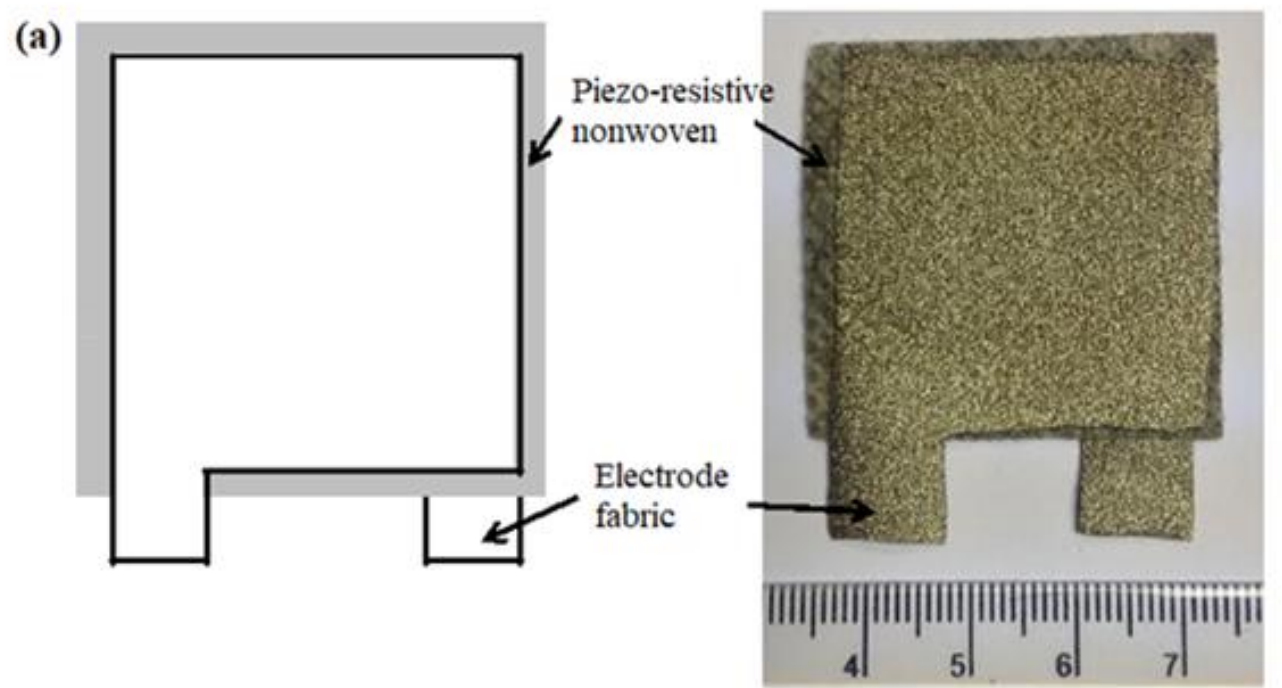

(b)

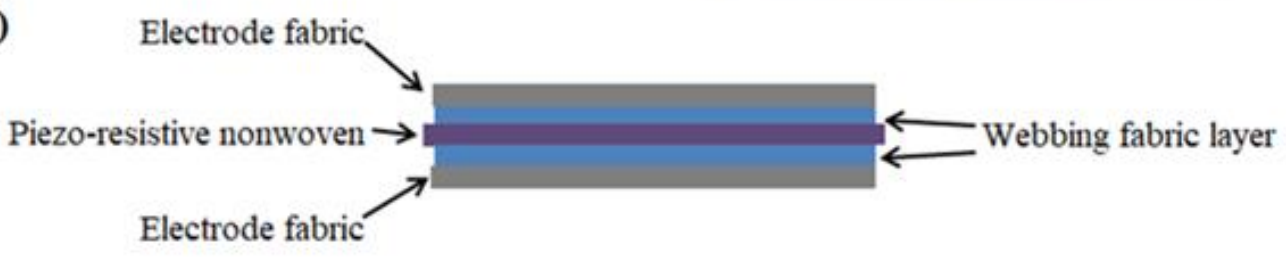

(c)

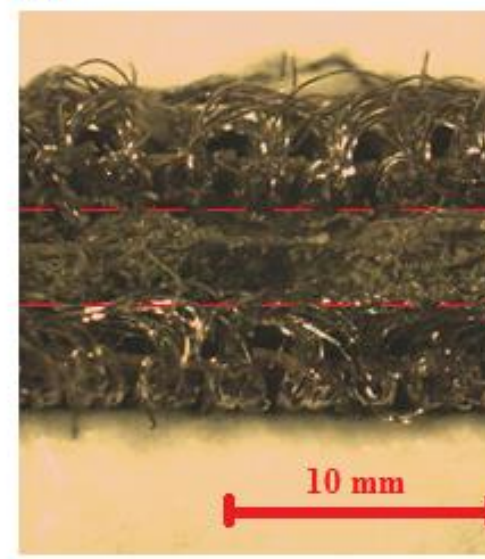

(d)

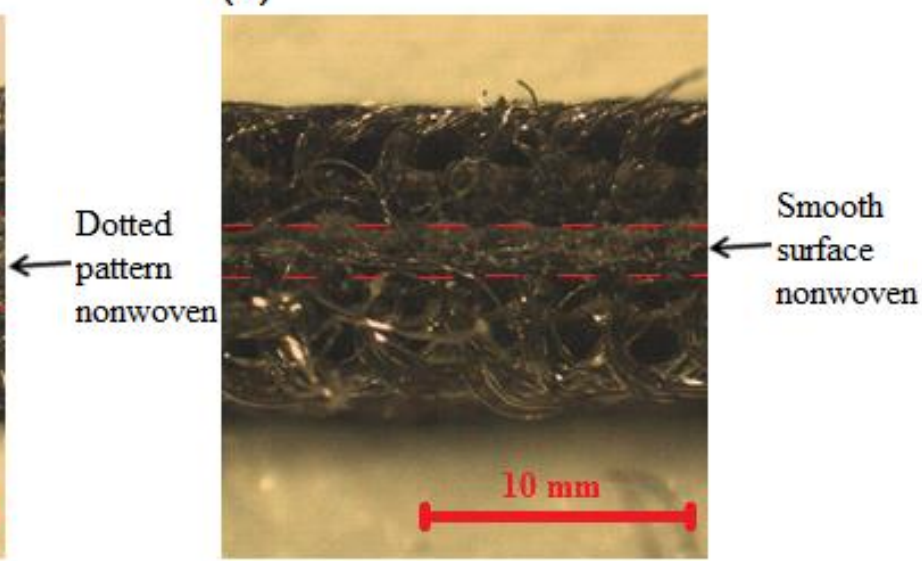

Figure 5. Structure of the nonwoven piezo-resistive sensor: (a) shows the sketch and the photo of the sensor; (b) shows the layers of materials forming the piezo-resistive nonwoven sensor; (c) and (d) show the cross-section images of the piezo-resistive sensors with the dotted pattern nonwoven fabric and the smooth surface nonwoven fabric.

\subsection{Measurement of electrical resistance}

In this research, due to the fact that the piezo-resistivity of the sensor material was investigated mainly by measuring the change in the electrical resistance, the half-bridge circuit was used throughout all types of tests involving electrical resistance measurement 
and recording. The piezo-resistive sensor $\left(R_{\text {Sensor }}\right)$ and a resistance box $\left(R_{R-b o x}\right)$ were connected to form the half-bridge circuit, as illustrated in Figure 6.

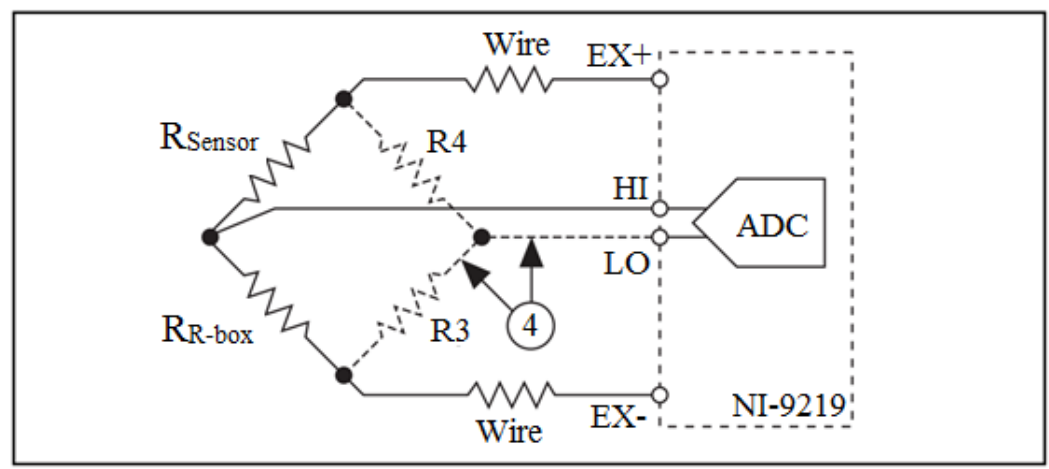

Figure 6. The Wheatstone half bridge circuit diagram was used to measure the resistance of the piezo-resistive sensor in this research. The dotted lines are the circuit built into the data acquisition card [35].

The NI-9219 data acquisition card was able to measure and record the $\frac{U_{H I-L O}}{U_{E X}}$ reading during the tests. In order to acquire a continuous resistance signal under dynamic conditions, the following method was conducted.

1) The bridge was balanced using the resistance box before starting the tests, and the reading of the resistance box was noted.

2) The test was carried out while the $\frac{U_{H I-L O}}{U_{E X}}$ readings were recorded by NI-9219 data acquisition card.

3) The following equation was applied in order to calculate the dynamic electrical resistance of the sensor.

$$
R_{\text {Sensor }}=R_{R-b o x} \times \frac{1-2 \times \frac{U_{H I-L O}}{U_{E X}}}{1+2 \times \frac{U_{H I-L O}}{U_{E X}}}
$$

\subsection{Electro-mechanical quasi-static compression test}

Each sample was conditioned under a standard humidity of $65 \% \mathrm{RH} \pm 5 \% \mathrm{RH}$ and $23{ }^{\circ} \mathrm{C}$ $\pm 0.6{ }^{\circ} \mathrm{C}$ for at least 24 hours before testing based on ASTM D1776. The quasi-static compression test was carried out using Zwick/050 tensile tester. Each sample was compressed between two compressive plates, the size of which was $40 \mathrm{~mm}$ by $40 \mathrm{~mm}$. The test speed was $1 \mathrm{~mm} /$ minute in order to eliminate the effect of the testing speed on the sensor performance. In order to define the transient performance of the electromechanical tests, the performance of the sensors was investigated initially at $0.1 \mathrm{kPa}, 0.2$ $\mathrm{kPa}$ and $0.5 \mathrm{kPa}$. After the initial period, the resistance readings were recorded at $0.5 \mathrm{kPa}$ intervals up to $10 \mathrm{kPa}$. The resistance of the sensor was recorded by using the Wheatstone bridge mode in a data acquisition card (NI-9219). Five samples of each type of the piezoresistive nonwoven sensor were tested. 


\subsection{Cyclic compressive loading}

The reproducibility of the piezo-resistive nonwoven sensor was investigated by carrying out cyclic compressive load tests. With the help of Zwick/050 tensile tester, the piezoresistive nonwoven sensor samples were compressed from 0 to $10 \mathrm{kPa}$ for 20 cycles, at a deformation speed of $1 \mathrm{~mm} / \mathrm{min}$ for both loading and unloading cyclic. The electrical resistance was recorded simultaneously using the same settings as the quasi-static electromechanical compressive test.

\subsection{Cardiorespiratory tests}

The test setup for acquiring the cardiorespiratory signals is shown in Figure 7. In order to capture the cardiorespiratory signals, sufficient contact pressure is required between the piezo-resistive sensor and the test surface. A belt was used to tighten the piezo-resistive sensor patch onto the test subject's left chest area, in order to have a sensor contact pressure of $1.5 \mathrm{kPa}$ [36]. During the breathing signal capturing tests, the subject performed the following actions: normal breathing, breath holding, rapid breathing, lifting of his left arm and lifting of his right arm. In the case of heart signal capturing, the subject held his breath for 90 seconds. During the cardiorespiratory tests, the resistance of the sensor was recorded at all times using the NI-9219 data acquisition card at a sampling rate of $50 \mathrm{~Hz}$, to investigate the performance of the sensor and how the sensor would be interfered by the body movements.

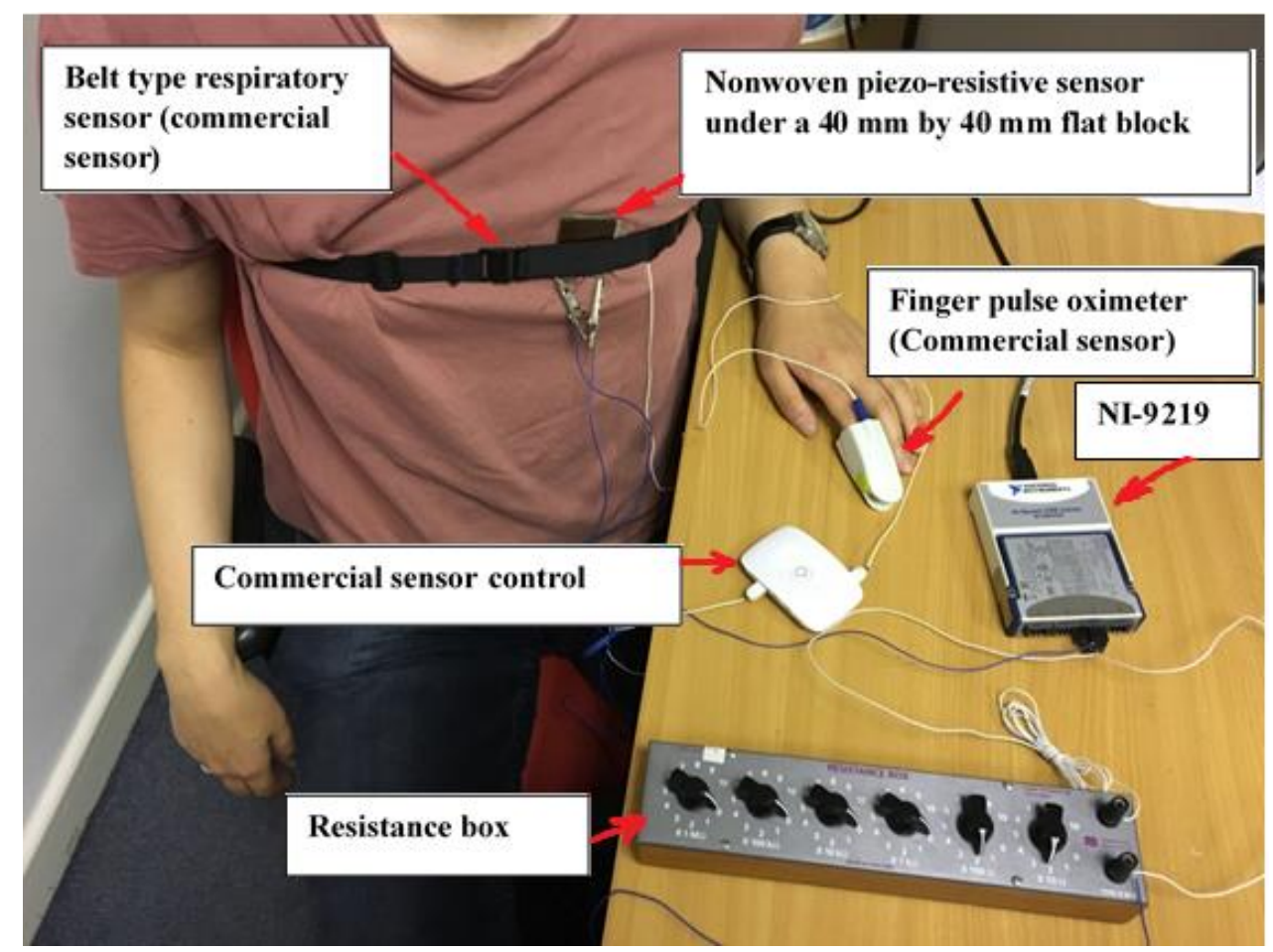

Figure 7. Sensor setups for cardiorespiratory signal capturing.

In order to improve the reliability of the electrical resistance signal generated by the sensor, a bandpass filter was applied. The frequency of the cardiorespiratory signals varies according to the situation of the subject. The respiratory signal normally is within 
the range of 0.1 to $0.5 \mathrm{~Hz}$; whereas the cardiac signal has a frequency from 1 to $1.67 \mathrm{~Hz}$ [37]. Considering the extreme conditions, the bandpass filter was set from 0.1 to $1 \mathrm{~Hz}$ for respiratory signal and 0.8 to $2 \mathrm{~Hz}$ for cardiac signals. The cardiorespiratory tests were carried out on five male and five female subjects.

\section{Results and discussion}

\subsection{The optimization of the sensor through modified structural and surface properties}

In order to investigate the effectiveness of the silver impregnated webbing fabric, the nonwoven piezo-resistive sensors A and B were firstly compared with two nonwoven sensors fabricated without the silver impregnated webbing fabrics, the results of which can be seen in Figure 8.

(a) Dotted pattern nonwoven sensor $\mathrm{A}$

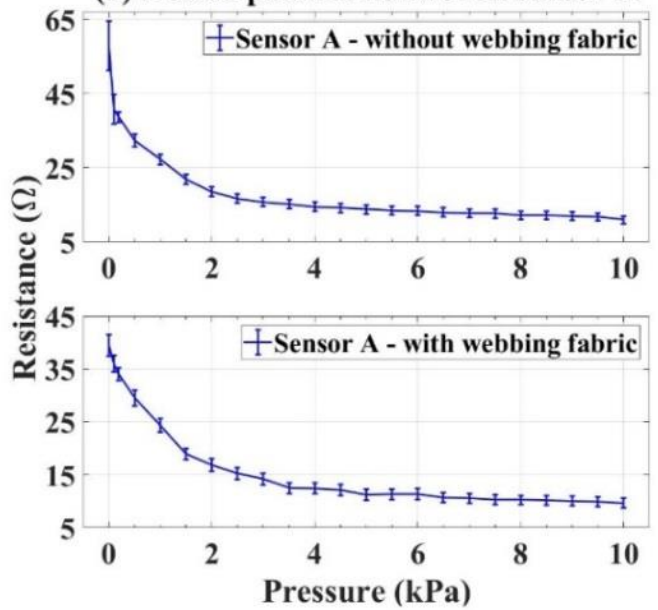

(c) Smooth pattern nonwoven sensor B

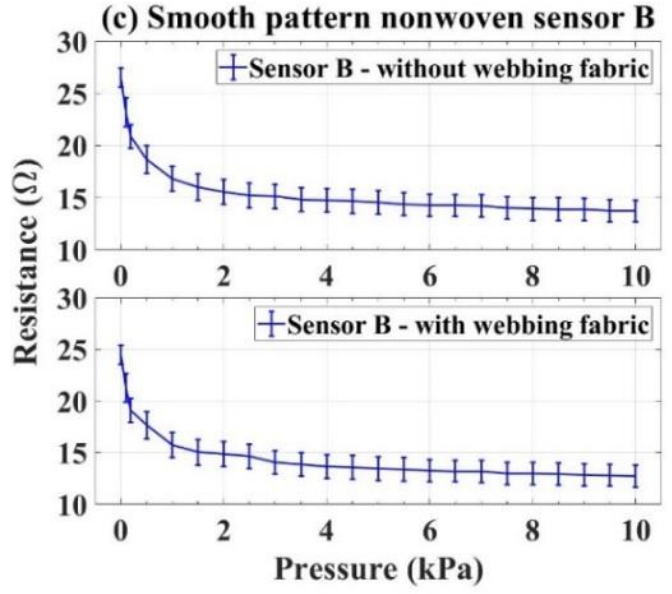

(b) Dotted pattern nonwoven sensor $\mathbf{A}$

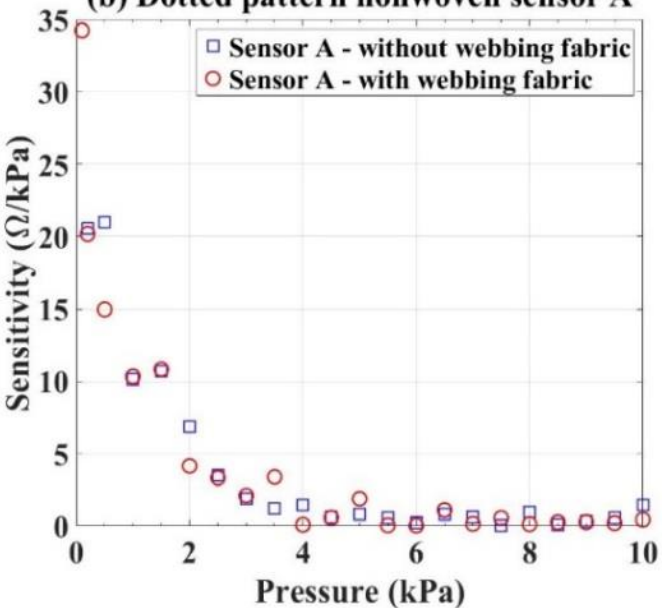

(d) Smooth pattern nonwoven sensor $B$

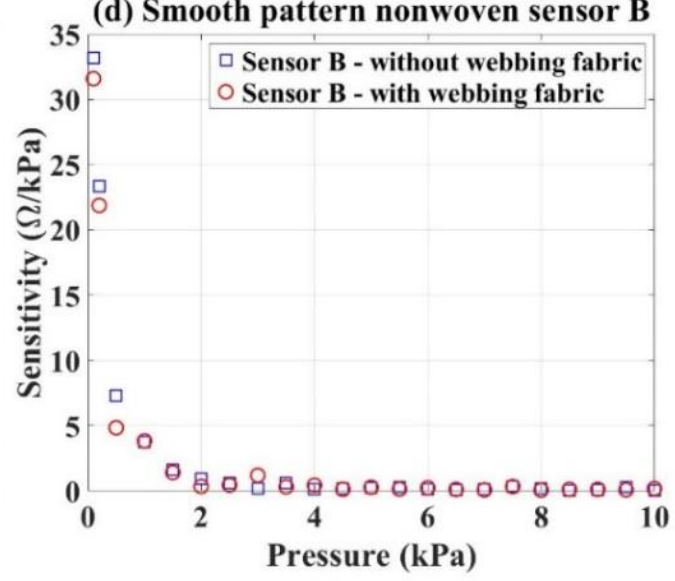

Figure 8. Characterization of sensors constructed with two types of nonwoven materials: (a) and (c) show resistance variation with respect to pressure variation for a dotted surface pattern (which takes-up 30\% silver contents) and a smooth surface pattern (which takes-up 68\% silver contents) nonwoven respectively; (b) and (d) show sensitivity of the sensor with respect to pressure variation for a sensor constructed from the dotted surface and the smooth surface respectively. 
The resistance vs. pressure characteristic curves of the piezo-resistive sensors derive from the electrical connections made by the electroconductive nanoparticles during the sensor compression. Majority of these electrical connections are made during compression of the material up to $2 \mathrm{kPa}$. Therefore the non-linear characteristic curves show the largest gradient for pressures up to $2 \mathrm{kPa}$. As Figure 8a and Figure 8c show, the nonwoven sensors without the silver impregnated webbing fabrics started with large error bars at lower pressures, which is due to the insufficient electrical contact between the knitted silver electrode and the nonwoven piezo-resistive fabric. At a low compressive force on the sensor (zero pressure in the present case), the fiber arrangement tends to have a large variation in the fiber to fiber distance in each test, which eventually causes resultant large variations in the initial resistance. As the pressure is increased, the error bars (standard error) can be seen to decrease for the dotted pattern nonwoven sensor (Figure 8a). By introducing the silver impregnated webbing fabric layers, there is an immediate resultant reduction in the error bars in the characteristic curve. The silver impregnated webbing fabric layers were used to bind the knitted electrode and electro-conductive nonwoven layers in the sensor to stabilize the sensor performance. By adding the additional silver impregnated webbing fabric layers, the overall resistance of the sensor was decreased for both types of sensors, which was due to the better electrical contact between the knitted silver electrode and the nonwoven layer. The piezo-resistance sensitivity $(S)$ of the sensor material was calculated based on the equation for the coefficient of the piezo-resistive material and normalized over pressure, described as follows:

$$
S=\Delta R / \Delta P
$$

where: $\Delta R / \Delta P$ is the measured change in sensor resistance per unit change in pressure at $P$, where $P$ is the pressure value during the test.

However, this modified construction did not improve the sensitivity of the piezo-resistive sensor significantly as shown in the Figure 8b and Figure 8d, where the sensitivity of the piezo-resistive nonwoven sensor is seen to reduce as the pressure increases. As the nonwoven material gets closer to the fully compressed state, it has a reduced chance of creating additional electrical paths within the silver impregnated nonwoven material. The highest sensitivity points for both types of the nonwoven sensors are seen at $0.1 \mathrm{kPa}$ (for dotted pattern nonwoven sensor without the silver impregnated webbing fabrics, as the relatively large change in resistance causes a sensitivity value of $171.15 \Omega / \mathrm{kPa}$, which is not shown in Figure 8b); however, considering the inaccuracy caused by the large error bars, it is not suitable to use the sensor at such low pressure levels. The sensitivity of both types of nonwoven sensors shows a relatively flat curve after exceeding a pressure value of $2 \mathrm{kPa}$. However, within the pressure range between 1 and $2 \mathrm{kPa}$, the nonwoven sensors show an optimum piezo-resistive sensitivity (an average sensitivity of $8.433 \Omega / \mathrm{kPa}$ and $1.865 \Omega / \mathrm{kPa}$ for the dotted pattern and smooth pattern nonwoven sensors, respectively). The sensor constructed with the impregnated dotted pattern nonwoven layer showed a higher piezo-resistive sensitivity than the sensor constructed with a smooth surface nonwoven. This would be due to the difference in the area density of the two nonwoven fabrics. Since the dotted pattern nonwoven fabric has a lower area density, resulting in higher compressibility. Therefore under compression, the change in the resistance of the dotted pattern nonwoven sensor is higher than that of the smooth pattern nonwoven. 
Therefore, even though the silver take-up in the dotted pattern nonwoven sensor is lower $(30 \%)$, this material shows higher sensitivity.

\subsection{Cyclic compressive loading}

It can be seen in Figure 9 that both sensors show satisfactory repeatability after 20 cycles of continuous loading and relaxing and induce a hysteresis in the resistance-pressure curves.
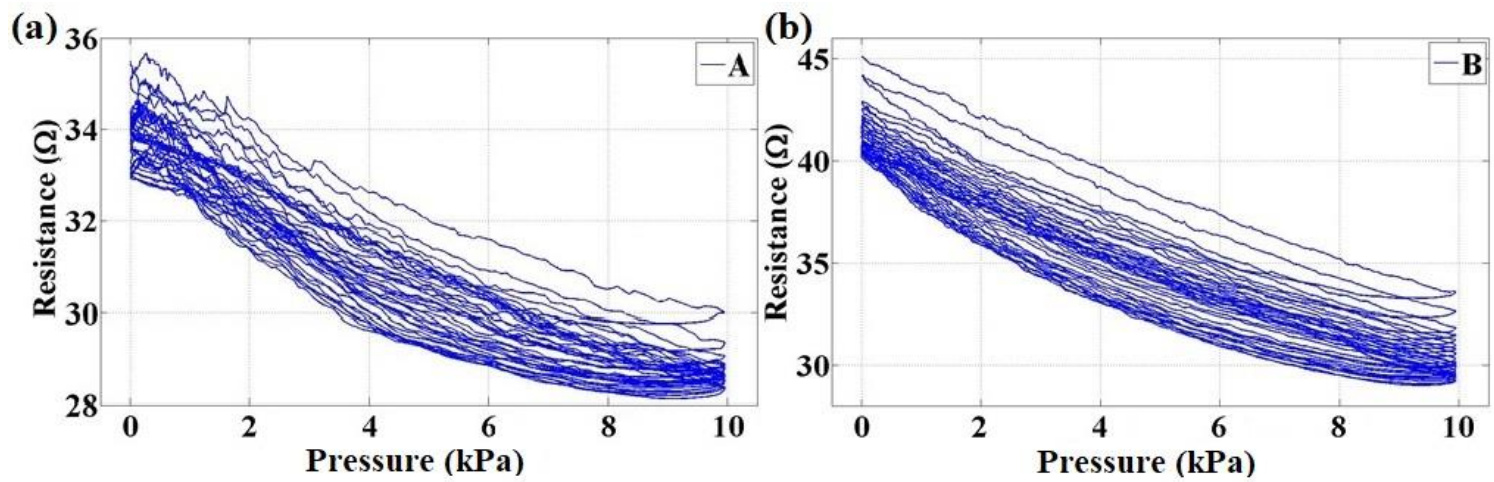

Figure 9. Cyclic compressive load resistance vs. pressure curves of sensors A and B.

In order to evaluate the hysteresis effect of the electrical resistance of the nonwovenbased pressure sensor, similar to the hysteresis loss calculations for mechanical cyclic loading tests [38-40], the resistance hysteresis loss $\left(R_{H L}\right)$ and the percentage of the $R_{H L}$ for each cycle were calculated based on the following equations.

$$
\begin{aligned}
\text { Resistance hysteresis loss }\left(R_{H L}\right) & =R P_{L}-R P_{U} \\
R_{H L} \% & =\frac{R_{H L}}{R P_{L}} \times 100 \%
\end{aligned}
$$

where: $R P_{L}$ and $R P_{U}$ are the areas under the loading and unloading curves for each cycle, respectively.

The two thermally bonded nonwoven fabric sensors (sensor A and B) both can be seen to have conditioning effects during the cyclic loading; they both have stable hysteresis loss percentages of $2.10 \%$ and $2.15 \%$ in average, for sensor A and B respectively. The difference in the hysteresis loss value is due to the difference in the sensor resistance which is an inevitable result from the different silver take-up percentages due to different fabric properties.

It is noticeable that during cyclic loading, the resistance of the sensor gradually reduces as the cyclic compressive test progresses. This phenomenon is studied by normalizing the resistance at the peak $\left(R_{\text {peak }}\right)$ and the trough $\left(R_{\text {trough }}\right)$ in each compressive loading cycle to the resistance at the first peak $\left(R_{\text {peakl }}\right)$ and trough $\left(R_{\text {troughl }}\right)$. 

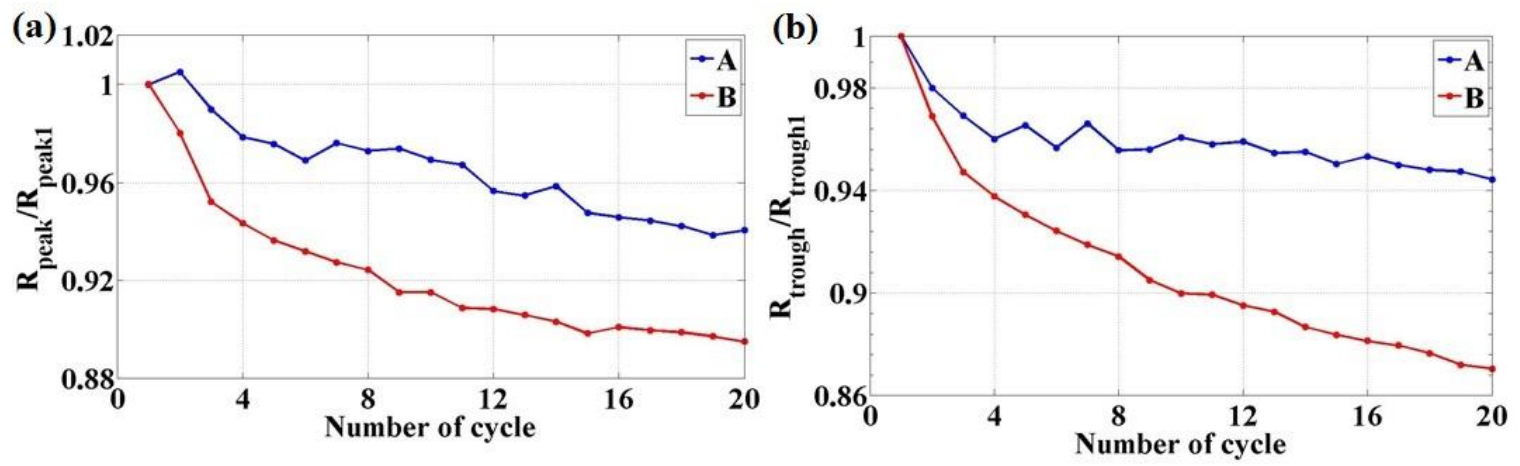

Figure 10. The change of (a) peak resistance and (b) trough resistance in each cycle.

As seen in Figure 10, sensor A shows better adaptability to the cyclic compressive loading than sensor $\mathrm{B}$. The resistance change of sensor $\mathrm{A}$ at the peaks and trough over 20 cyclic loadings is around 5\%, while for sensor B is over 10\%. This could happen as a result of the different levels of bonding in the nonwoven structure of sensor A and B. Due to the nonwoven material construction methods, sensor A material has fully bonded areas only in the embossed dotted pattern while in sensor B, the fibers are fully bonded. The dotted pattern embossed surface structure allows the nonwoven fabric to absorb more energy from pressure without deforming significantly. Once the pressure is removed, the surface structure which is not thermally bonded is able to recover sooner than other thermally bonded nonwoven fabrics.

The response and releasing time of the developed piezo-resistive nonwoven sensors were investigated by applying periodical dynamic pressures varying from 1 to $2 \mathrm{kPa}$ (the sensitive region as mentioned in 4.1), at $0.1 \mathrm{~Hz}$ and $0.5 \mathrm{~Hz}$ frequencies. As can be seen in Figure 11a and Figure 11c, there is an immediate change in the resistance of sensor $A$ as soon as the pressure changes. As expected, due to higher frequency of $0.5 \mathrm{~Hz}$, both the pressure signal and the corresponding resistance signal of the piezo-resistive nonwoven sensor showed some fluctuation during the idling period. The response time of sensor A under $0.1 \mathrm{~Hz}$ frequency and $0.5 \mathrm{~Hz}$ frequency was $0.48 \mathrm{~s}$ and $0.41 \mathrm{~s}$, respectively; while the releasing time of sensor A was $0.22 \mathrm{~s}$ and $0.23 \mathrm{~s}$ for $0.1 \mathrm{~Hz}$ and $0.5 \mathrm{~Hz}$ frequencies, respectively. It is worth noting that due to the fact that the dynamic pressure signal was applied by a screw type tensile tester (Zwick/050), there is a time delay of $0.21 \mathrm{~s}$ and 0.13 $\mathrm{s}$ for the pressure to reach and settle at its target value. Therefore, the actual response time and the releasing time of sensor A could be even lower. On the other hand, as can be observed in Figure 12, the resistance signal of sensor B shows a stronger resistance time drift phenomenon than sensor $\mathrm{A}$. The response time and releasing time of sensor $\mathrm{B}$ at 0.1 $\mathrm{Hz}$ frequency is $0.53 \mathrm{~s}$ and $0.25 \mathrm{~s}$, respectively. Compared with sensor $\mathrm{A}$, the respond time of sensor B is slightly longer, which could be due to the fact that sensor B with a smooth surface pattern has a worse recoverability from compression than sensor A embossed with a dotted surface pattern. The result of sensor B at $0.5 \mathrm{~Hz}$ frequency was found fluctuating, due to which the response time and releasing time was not able to be calculated. This again is due to the poor compressive recoverability of sensor B. 

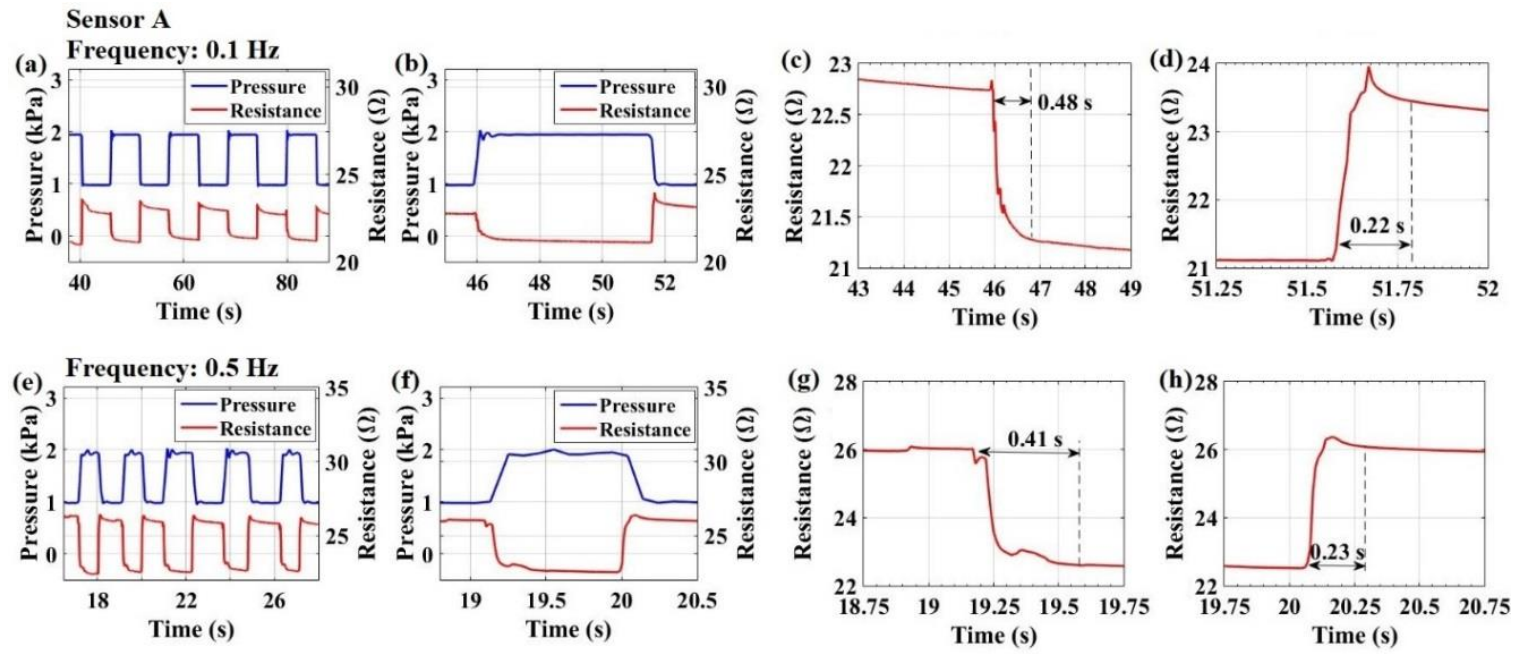

Figure 11. The response and releasing time of the piezo-resistive nonwoven sensor A: (a) and (b) show the pressure response of sensor A at $0.1 \mathrm{~Hz}$; (c) and (d) show the corresponding response and releasing time of sensor A at $0.1 \mathrm{~Hz}$; (e) and (f) show the pressure response of sensor $\mathrm{A}$ at $0.5 \mathrm{~Hz} ;(\mathrm{g})$ and $(\mathrm{h})$ show the corresponding response and releasing time of sensor $\mathrm{A}$ at $0.5 \mathrm{~Hz}$.
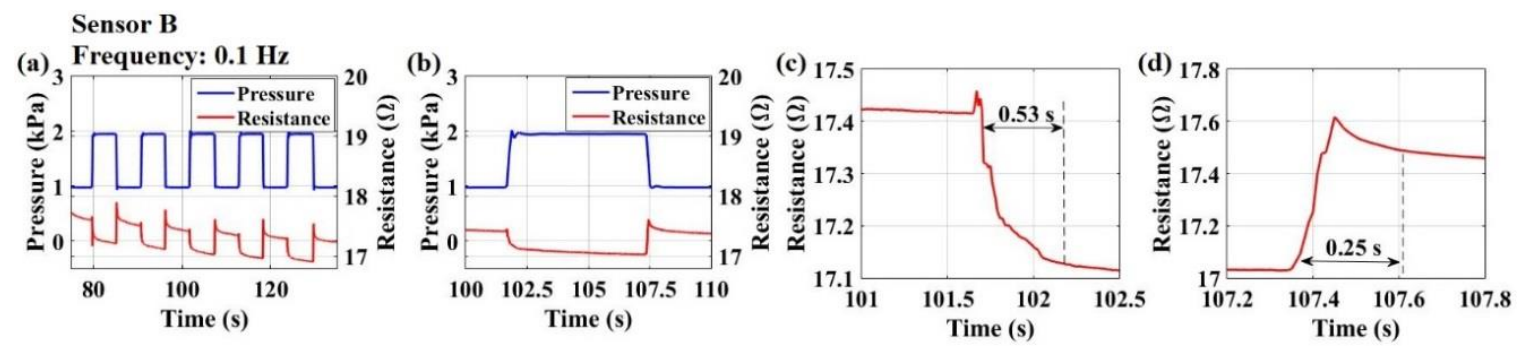

Figure 12. The response and releasing time of the piezo-resistive nonwoven sensor B: (a) and (b) show the pressure response of sensor B at $0.1 \mathrm{~Hz}$; (c) and (d) show the corresponding response and releasing time of sensor B at $0.1 \mathrm{~Hz}$.

\subsection{Cardiorespiratory signal acquisition}

The evaluation of the novel, silver based nonwoven piezo-resistive sensor A and B for their capacity for capturing the breathing signals and heart signals were carried out separately within the pressure range of 1-2 $\mathrm{kPa}$. In each case, the procedure was selected in order to clearly visualize the sensor's capacity for signal capture during breathing and while holding the breath.

\subsubsection{Breathing signal acquisition}

The test procedure used for acquiring the breathing signal consists of four repeats of normal breathing followed by holding the breath (each repeat has 30 seconds of normal breathing followed by 30 seconds of holding the breath). These four repeats were followed by rapid breathing for 60 seconds and normal breathing for 30 seconds. In order to observe the capacity of the sensors to capture the breathing signal during body movement, further testing was carried out while the test subject was lifting and lowering the right arm for three times, and the left arm for three times. A commercially available 
BCG sensor was used together with the nonwoven sensors approximately at the same time, following the same test procedure, in order to verify the results.

The test results shown in Figure 13 were acquired using sensor A. It can be seen clearly in Figure 13 that the peaks of the signal of the piezo-resistive nonwoven sensor A match perfectly with those of the commercially available breathing belt-sensor. During the time the subject held his breath, the piezo-resistive nonwoven sensor A was seen to capture less noise than the commercially available sensor. In the breathing test shown in Figure 13a, for each lifting and lowering movement of the arm, the piezo-resistive nonwoven sensor A shows a single upward spike while the commercial sensor detected upward and downward spikes (which is characteristic to the sensor type used in the commercial sensor system) during the breathing cycle motion artifact investigation.

In Figure 13a, it can be seen that the left arm movements affect the signal more than the right arms movements. This is because that the sensor patch was attached on the left side of the subject's chest. It is observed that during normal breathing and rapid breathing, the signal amplitude in the commercially available belt sensor is higher than that of the nonwoven sensor A. However, it can also be observed that after the arm movements, the piezo-resistive nonwoven sensor A captured the breathing signals almost immediately while the commercially available sensor failed to do so. The close agreement of peaks between the nonwoven sensor A and the commercially available sensor verifies the accuracy of the nonwoven sensor A. As marked in the red circle in Figure 13a, whenever the left arm was lowered, the commercially available sensor missed a breathing peak; however, the nonwoven sensor A was able to capture the complete breathing signal. This shows the nonwoven sensor A has better reliability than the commercially available sensor in this situation. This may be because that the commercially available belt sensor was a strain sensor which works on the principle of extension in length due to the increase in the girth of the chest while breathing. However, the body movements caused by the arm lifting neutralized the change of the girth of the chest due to the breathing activity, resulting in the missing peaks of the commercially available breathing sensor. It is observed that breathing signal and arm lift has interference peaks shown in Figure 13a. That may also be the reason for the widening of peaks at those points for belt sensor. In the case of the piezo-resistive nonwoven sensor A, the arm lifting had less interference with the sensor functionality. This effect was observed in the breathing signals of the other subjects tested during this research.

As observed in Figure 13b while capturing the normal breathing signals, both the nonwoven sensor A and the commercially available sensor performed equally well. Since the commercially available sensor is based on a stretchable belt and the nonwoven sensor is a multi-layer fabric pressed against the chest, the signals acquired from the two types of the sensors tend to be in the opposite sense. Despite the difference in the sensor technologies between the commercially available sensor and the piezo-resistive nonwoven sensor A, the results still show that the piezo-resistive nonwoven sensor $\mathrm{A}$ has the full capability of acquiring the correct breathing signals. Similarly to the normal breathing signals, sensor A was capable of capturing the rapid breathing signals accurately, as may be seen in Figure 13c. 

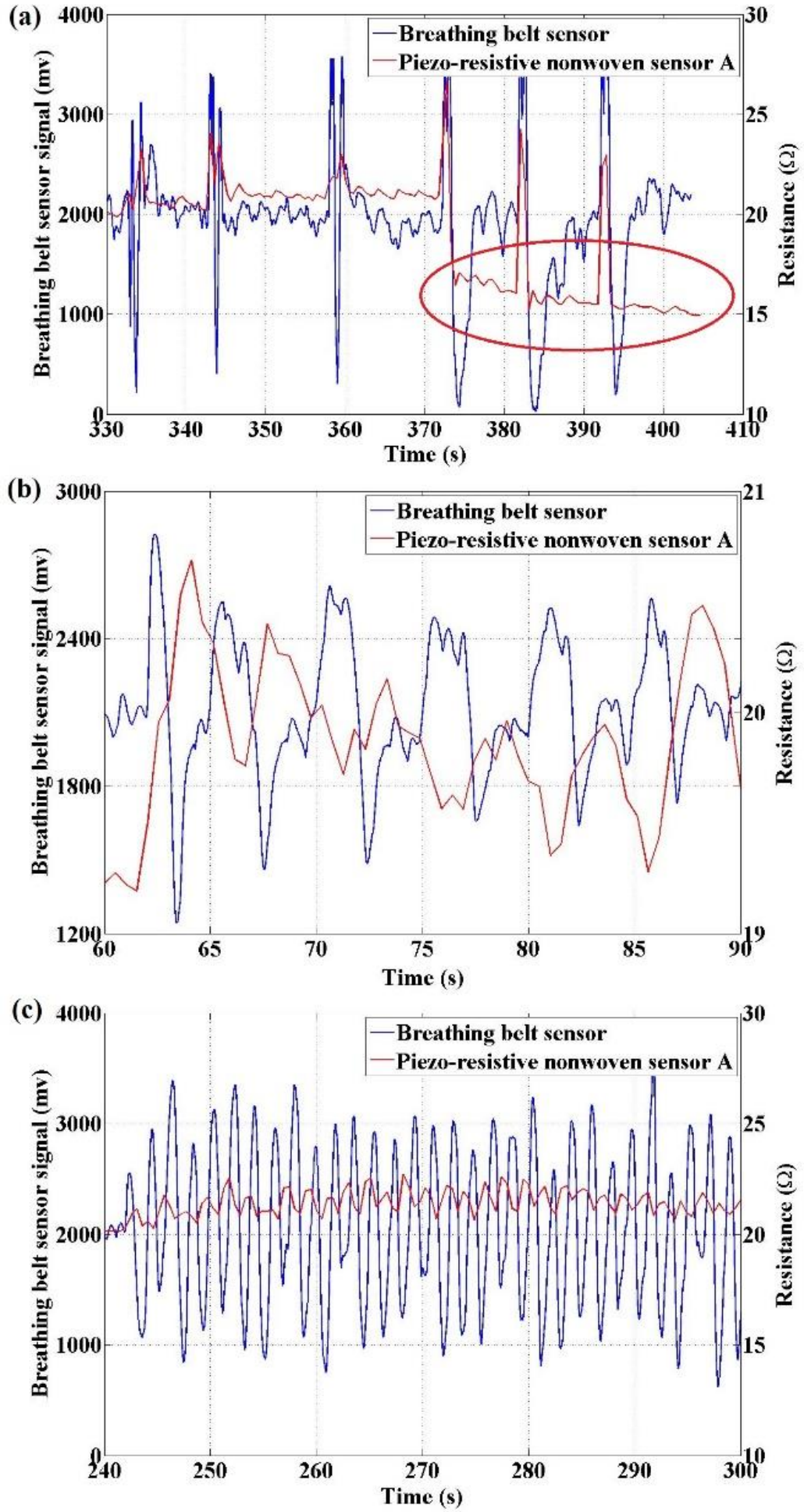

Figure 13. Breathing signal curve from the commercially available breathing belt sensor and the piezo-resistive nonwoven sensor A: (a) shows the arm movement interferences to the sensor performance; the red circle indicates the additional peaks picked up by the piezo-resistive nonwoven sensor; (b) scales the peaks detected during the normal breathing; (c) shows the rapid breathing signal. 

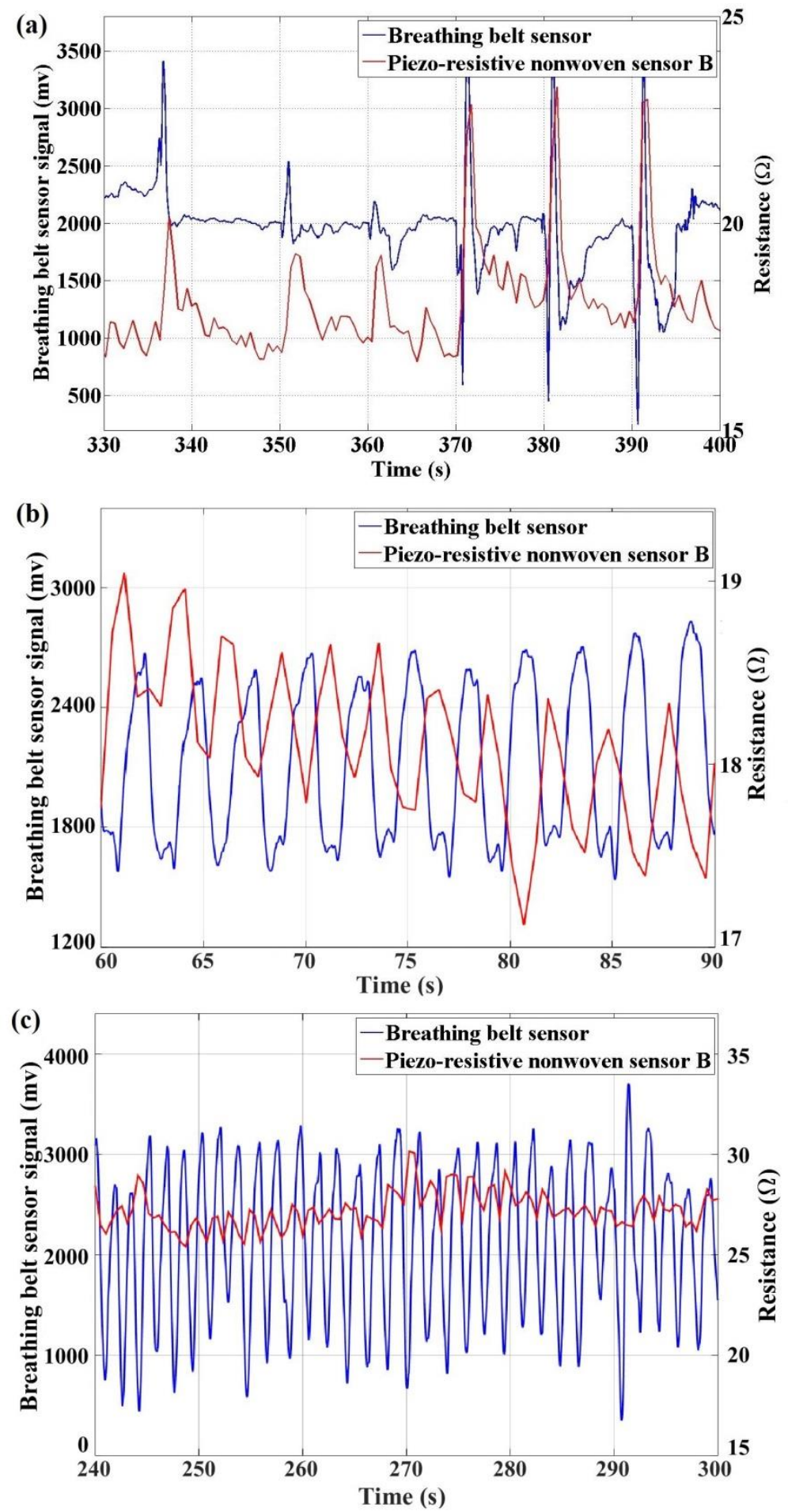

Figure 14. Breathing signal curve from the commercially available breathing belt sensor and the piezo-resistive nonwoven sensor B: (a) shows the arm movement interferences to the sensor performance; (b) scales the peaks detected during the normal breathing; (c) shows the rapid breathing signal. 
Similar results were observed when using the smooth piezo-resistive nonwoven sensor (sensor B) where each test period corresponding to the movements of the subject can be clearly identified from the breathing signals (as illustrated in Figure 14). Figure 14a illustrates that although the arm lifting movements were successfully captured, both the piezo-resistive nonwoven sensor B and the commercially available sensor respond poorly in capturing the breathing signals following strong arm movement. The rapid breathing result in Figure 14c shows that the piezo-resistive nonwoven sensor B failed to perform reliably during the rapid breathing period. The signals recorded consist of a large amount of fluctuation and a limited amount of peaks that could be matched with the control signal. The reason for such could be the strong chest movement during the rapid breathing, causing a higher pressure to be applied on the sensor fabric. As the pressure increased, the sensitivity and the change in resistance of the sensor decreased; resulting in a poor quality captured breathing signal.

Comparing sensors A and B, it is evident that in capturing the breathing signal, Sensor A performed better. Sensor A was able to respond correctly and accurately to the rapid breathing signal and successfully bypassed the interferences caused by the arm movements.

\subsubsection{Heartbeat signal acquisition}

The heartbeat signal was acquired using a commercially available finger clamp BCG sensor and the piezo-resistive nonwoven sensors A and B, while the subject held his breath for 90 seconds. During this period, as the breathing was suppressed, a much weaker heartbeat signal was expected to be captured.

In Figure 15, the results of the piezo-resistive nonwoven sensor show significant fluctuations in the general trend of the signal, yet heartbeats are still captured by the nonwoven sensor A. It can be observed that in the 'Drift Period' the resistance of the sensor reduces, which is due to the subject having to hold his chest non-moving to accommodate the long duration of breath holding. The green arrow shows the starting point when the subject was forced to move due to the discomfort in holding the breath; therefore, compared to the rest of this signal curve, 'Drift Period' provides a better clarity of the heartbeat signal. The tall peaks appeared during the 'Drift Period' were caused by the body of the subject trying to avoid inhaling air. Figure 15b illustrates the heart signal captured by the piezo-resistive nonwoven sensor, peaks of which approximately matches (19 heartbeats picked by sensor A compared with 20 picks from the BCG sensor) with the heart signal acquired by the commercially available BCG sensor. It should be noted that the finger clamp provided the commercial sensor good contact pressure with the skin, while the piezo-resistive sensor was placed on a relatively flat area of the chest resulting in a small contact pressure. As observed in Figure 15b, the heartbeat signal of the piezoresistive sensor A has lower amplitude compared to the commercial sensor; however, the peaks are identifiable. 

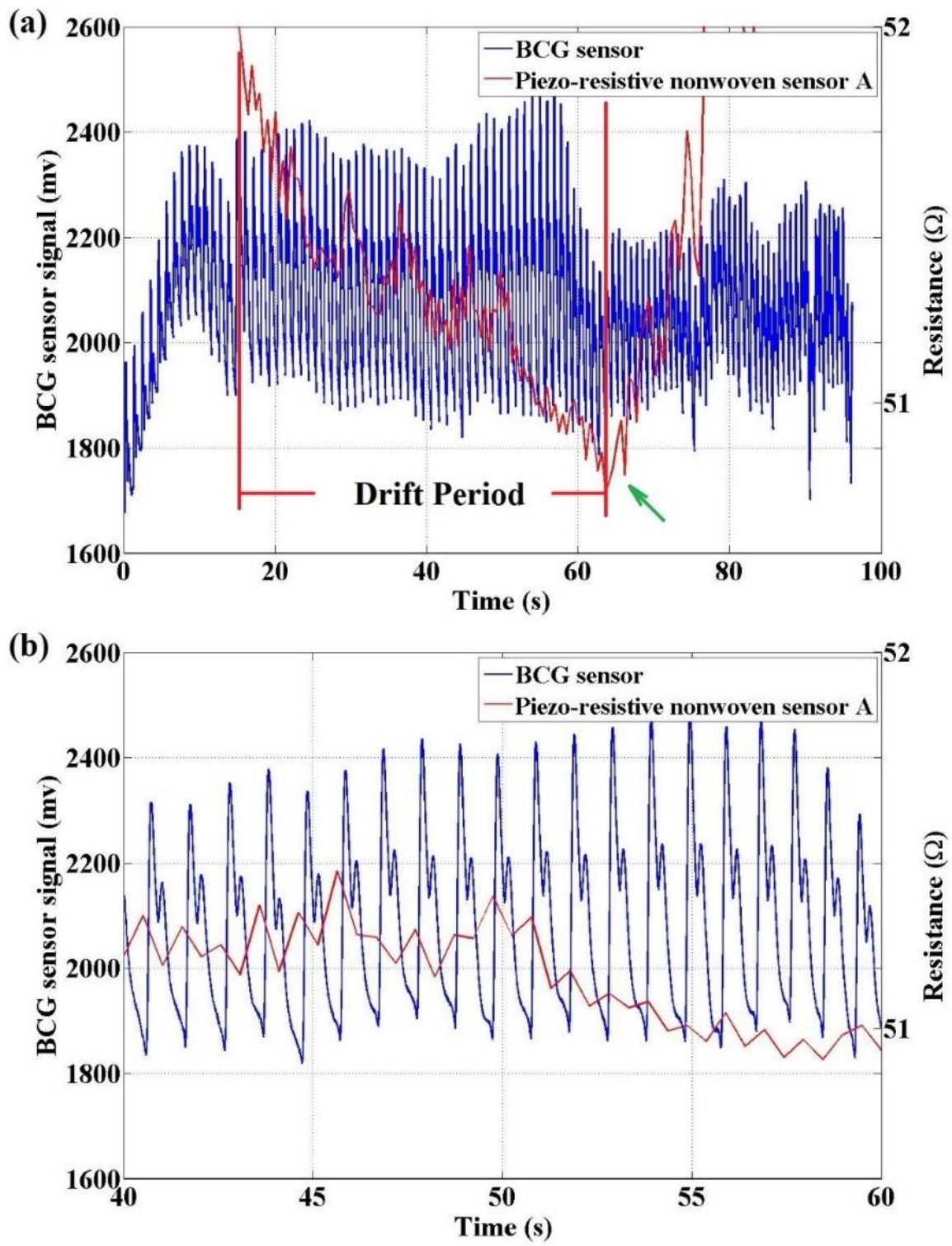

Figure 15. Heartbeat signal curve from the commercially available BCG sensor and the piezo-resistive nonwoven sensor A: (a) illustrates the overall heartbeat signal; in 'Drift Period', the non-uniformity in the signal was caused as a result of the subject trying to avoid chest movement while holding his breath; (b) shows the successful signal acquisition.

The results of using the piezo-resistive nonwoven sensor B for capturing the heartbeat signals are shown in Figure 16. Compared with sensor A, the result of sensor B shows more fluctuation. This is as expected since sensor B was found to show strong fluctuation in the signal at and above $0.5 \mathrm{~Hz}$ frequency in the sensor time response tests. Additionally, as illustrated in Figure 16b, at the selected period of time, only a few of the heartbeat signals were picked by the nonwoven sensor B. Although most part of the curve shows irrelevance to the heart signal, every peak that appears in the curve correlated to a peak in the curve from the commercially available BCG sensor. 

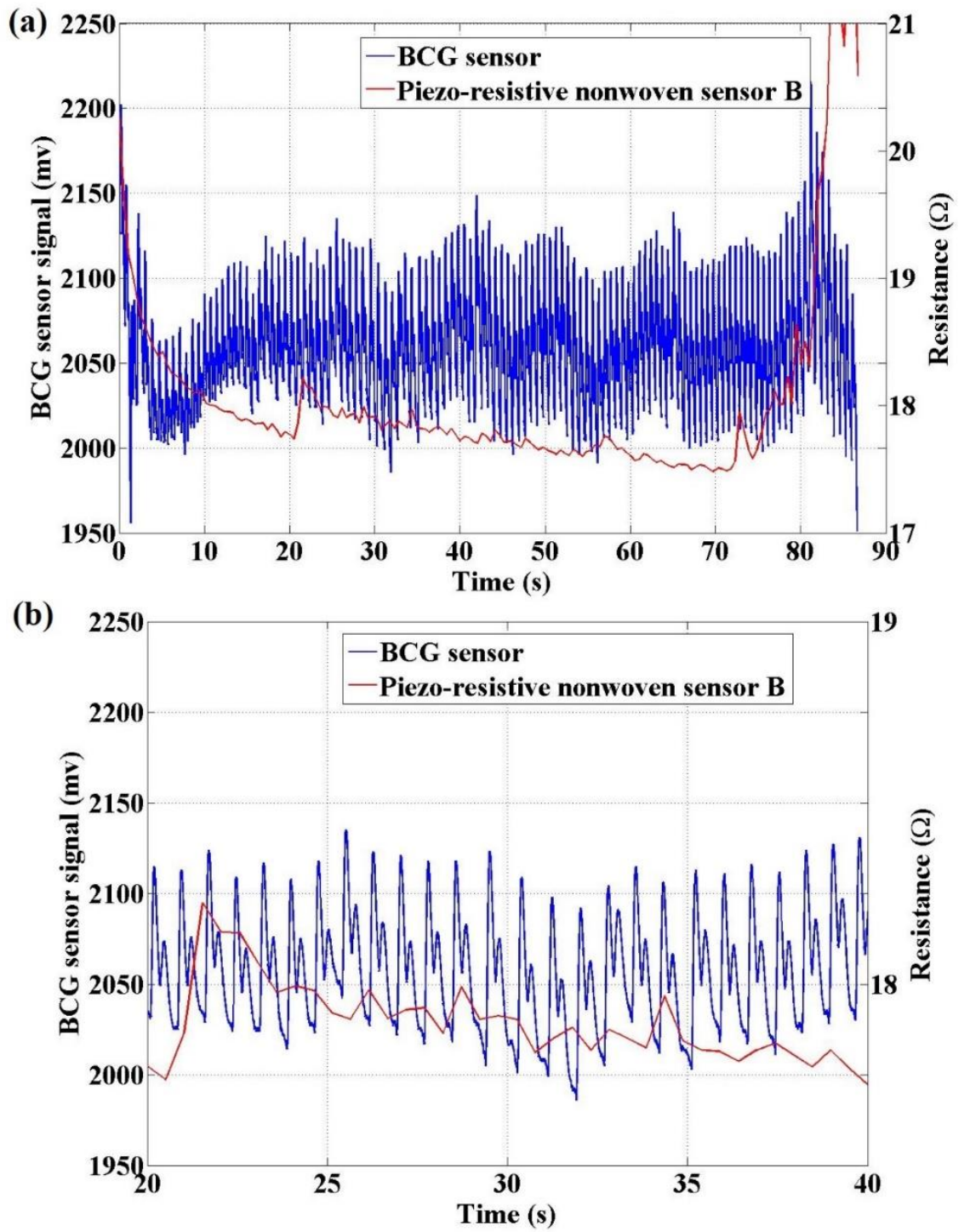

Figure 16. Heartbeat signal curve from the commercially available BCG sensor and the piezo-resistive nonwoven sensor B: (a) illustrates the overall heartbeat signal; (b) shows that the peaks picked by the nonwoven sensor B are correlated to the heartbeat signal acquired by the BCG sensor.

Comparing the dotted nonwoven fabric sensor (sensor A) with the smooth nonwoven fabric sensor (sensor B), the dotted nonwoven fabric sensor showed a better performance in capturing the heartbeat signal. This is because, within the operating range of $1-2 \mathrm{kPa}$, the sensitivity of the dotted nonwoven fabric is higher than the smooth nonwoven fabric. Therefore, for investigating the accuracy of the sensor, the tests were carried out using the dotted nonwoven fabric based sensor A.

\subsection{Investigation of the accuracy of the nonwoven piezo-resistive sensor}

For the investigation of the performance of the dotted nonwoven fabric when in use, five male and five female volunteers contributed their help for cardiorespiratory data 
collection. The cardiorespiratory data of a five-minute period of each volunteer were recorded with the control cardiorespiratory data (captured by the commercially available bio-signal sensing system).

The number and the locations of the peaks were detected and determined using a Matlab program that considers the criteria that the minimum distance between every two adjacent peaks needs to be 0.35 seconds and 3 seconds for heartbeat signals and breathing signals respectively. The amplitudes of the peaks are normalized as the fraction of the difference between the maximum and minimum amplitude.

Table 4 shows the statistical data of the ten volunteers' cardiorespiratory signal, from which it can be concluded that the nonwoven piezo-resistive sensor was reliable. Compared to the control data group, the nonwoven piezo-resistive sensor acquired the cardiorespiratory signals with less variation. The accuracy of the respiration rate $(R R)$ and heart rate $(H R)$ of the piezo-resistive sensor is calculated by the following equations:

$$
A_{R R}=\left(1-\frac{\left|\overline{R R_{B e l t}}-\overline{R R_{N S}}\right|}{\overline{R R_{B e l t}}}\right) \times 100 \%
$$

where: $A_{R R}$ is the accuracy of the $R R ; \overline{R R_{B e l t}}$ and $\overline{R R_{N S}}$ are the average $R R$ of the belt sensor and the nonwoven sensor, respectively.

$$
A_{H R}=\left(1-\frac{\left|\overline{H R_{B C G}}-\overline{H R_{N S}}\right|}{\overline{H R_{B C G}}}\right) \times 100 \%
$$

where: $A_{H R}$ is the accuracy of the $H R ; \overline{H R_{B C G}}$ and $\overline{H R_{N S}}$ are the average $H R$ of the BCG sensor and the nonwoven sensor, respectively. The discussion in the rest of this paper is based on the results from one of the volunteers. This signal was observed to be representative and typical when the subject is sitting down.

\begin{tabular}{|c|c|c|c|c|c|c|}
\hline \multirow{2}{*}{ Male } & \multicolumn{3}{|c|}{ No. of breathing/minute } & \multicolumn{3}{|c|}{ No. of heartbeat/minute } \\
\hline & Belt sensor & $\begin{array}{l}\text { Nonwoven } \\
\text { sensor }\end{array}$ & $\begin{array}{l}\text { Absolute } \\
\text { difference }\end{array}$ & BCG sensor & $\begin{array}{l}\text { Nonwoven } \\
\text { sensor }\end{array}$ & $\begin{array}{l}\text { Absolute } \\
\text { difference }\end{array}$ \\
\hline 1 & 13.93 & 12.96 & 0.97 & 70.04 & 72.17 & 2.13 \\
\hline 2 & 15.08 & 13.30 & 1.78 & 74.83 & 74.43 & 0.40 \\
\hline 3 & 15.07 & 12.69 & 2.38 & 57.52 & 69.82 & 12.30 \\
\hline 4 & 14.74 & 13.17 & 1.57 & 79.42 & 72.35 & 7.07 \\
\hline 5 & 11.87 & 12.19 & 0.32 & 7.053 & 75.59 & 5.06 \\
\hline Average & 14.14 & 12.86 & 1.28 & 70.47 & 72.87 & 2.4 \\
\hline Standard error & 0.60 & 0.20 & & 3.65 & 1.00 & \\
\hline Accuracy & & $90.95 \%$ & & & $96.59 \%$ & \\
\hline
\end{tabular}

Table 4. Cardiorespiratory data 


\begin{tabular}{lllllll}
\hline & \multicolumn{3}{l}{ No. of breathing/minute } & \multicolumn{3}{l}{ No. of heartbeat/minute } \\
\cline { 2 - 6 } Female & Belt sensor & $\begin{array}{l}\text { Nonwoven } \\
\text { sensor }\end{array}$ & $\begin{array}{l}\text { Absolute } \\
\text { difference }\end{array}$ & BCG sensor & $\begin{array}{l}\text { Nonwoven } \\
\text { sensor }\end{array}$ & $\begin{array}{l}\text { Absolute } \\
\text { difference }\end{array}$ \\
\hline 1 & 14.47 & 12.32 & 2.15 & 67.06 & 66.86 & 0.20 \\
2 & 15.16 & 13.43 & 1.73 & 71.38 & 71.38 & 0.00 \\
3 & 14.41 & 11.10 & 3.31 & 71.28 & 64.56 & 6.72 \\
4 & 15.02 & 12.45 & 2.57 & 75.30 & 70.95 & 4.35 \\
5 & 14.79 & 12.42 & 2.37 & 79.66 & 67.83 & 11.83 \\
Average & 14.77 & 12.34 & 2.43 & 72.94 & 68.32 & 4.62 \\
Standard error & 0.15 & 0.37 & & 2.13 & 1.28 & \\
Accuracy & & $83.55 \%$ & & & $93.67 \%$ & \\
\hline
\end{tabular}

\subsubsection{Heartbeat signal matching}

In the result of the peak detection and matching investigation (as shown in Figure 17), it is clear the signal amplitude variation of the nonwoven piezo-resistive sensor is significantly lower than that of the commercially available BCG sensor. Most of the peaks of the piezo-resistive nonwoven sensor are strong and clearly identifiable. In the peak location matching graph, a minor shift between two sets of peaks can be observed due to the natural difference between the working principles of the commercially available BCG sensor and the piezo-resistive nonwoven sensor. This is a result of the commercially available BCG sensor picking up the pulse on the finger and causing a delay in the signal.

The reproducibility of the electro-conductive nonwoven fabric based sensor in the application of capturing the cardiorespiratory signal was studied. The cardiorespiratory signals were acquired from the nonwoven sensor and commercially available sensor (Plux bio-signal system) and were repeated on the same subject for ten times. Each test lasted at least 5 minutes. The heartbeat count of these tests, from the piezo-resistive nonwoven sensor and the commercially available BCG sensor, normalized to the number of beats in one minute. Among ten tests, one of the test results was found unusual that the piezo-resistive nonwoven sensor obtained a heart rate of 91.98 beat/minute where the commercially available BCG sensor had only 72.92 beats/minute. The sensor performed as normal in the other nine tests. This unusual result could be due to the unexpected noise that affected the performance of the sensor. This issue should be able to be resolved if a better filtering system is applied. 

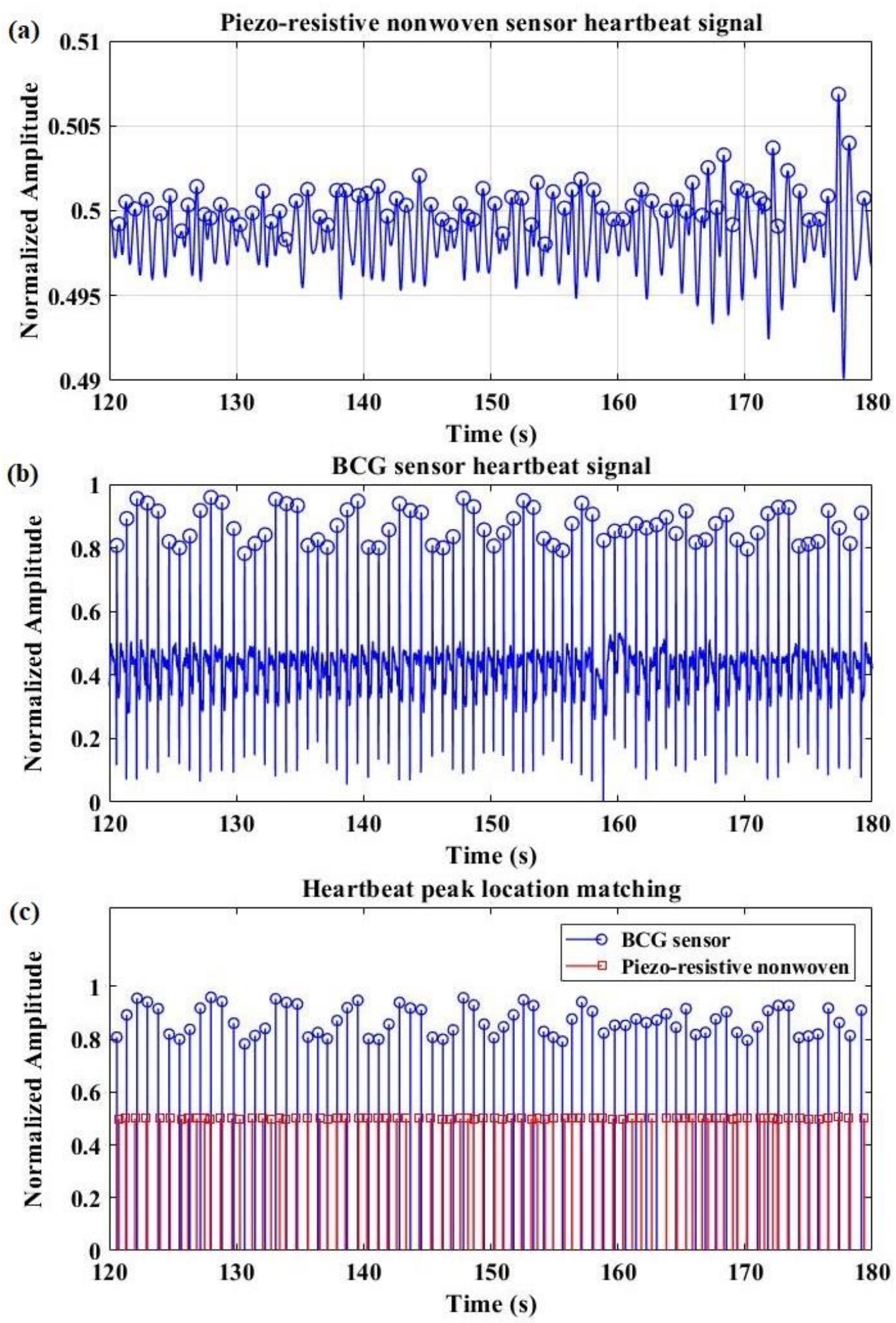

Figure 17. Heart signal peak detection and location matching between the nonwoven piezo-resistive sensor and commercially available BCG sensor. 
Table 5 illustrates that the heart rate of the commercially available BCG sensor and the nonwoven piezo-resistive sensor are comparable. While in some instances the heart rate figures from the piezo-resistive sensor were close to that of the commercially available sensor, in other instances a bigger gap was observed between them. This could be because of the poor contact pressure between the piezo-resistive sensor and the chest. It can be seen that the heart rate of the commercially available BCG sensor and the nonwoven piezo-resistive sensor are comparable. The piezo-resistive nonwoven sensor achieved a reliable performance with a standard deviation of 3.18 beats per minute and $92.83 \%$ of accuracy in detecting the cardiac signal.

Table 5. Heart rate (number of beats per minute) comparison

\begin{tabular}{lll}
\hline Test & Commercially available BCG sensor & Nonwoven piezo-resistive sensor \\
\hline 1 & 71.88 & 64.63 \\
2 & 71.88 & 73.93 \\
3 & 72.92 & 91.98 \\
4 & 71.43 & 77.71 \\
5 & 70.34 & 72.34 \\
6 & 72.05 & 79.64 \\
7 & 66.73 & 72.86 \\
8 & 73.39 & 70.86 \\
9 & 68.90 & 75.02 \\
10 & 65.82 & 76.88 \\
Average & 70.53 & 75.59 \\
Standard error & 1.15 & 3.18 \\
Accuracy & & $92.83 \%$ \\
\hline
\end{tabular}

4.4.2 Breathing signal matching

Figure 18 indicates the performance of the nonwoven piezo-resistive sensor while capturing the breathing signal, compared with the commercially available breathing belt sensor. The peaks of the signal captured by the nonwoven piezo-resistive sensor are clearer than those of the commercially available sensor system. However, there are false peaks detected in using the Matlab coding (marked in Figure 18a and Figure 18c). 

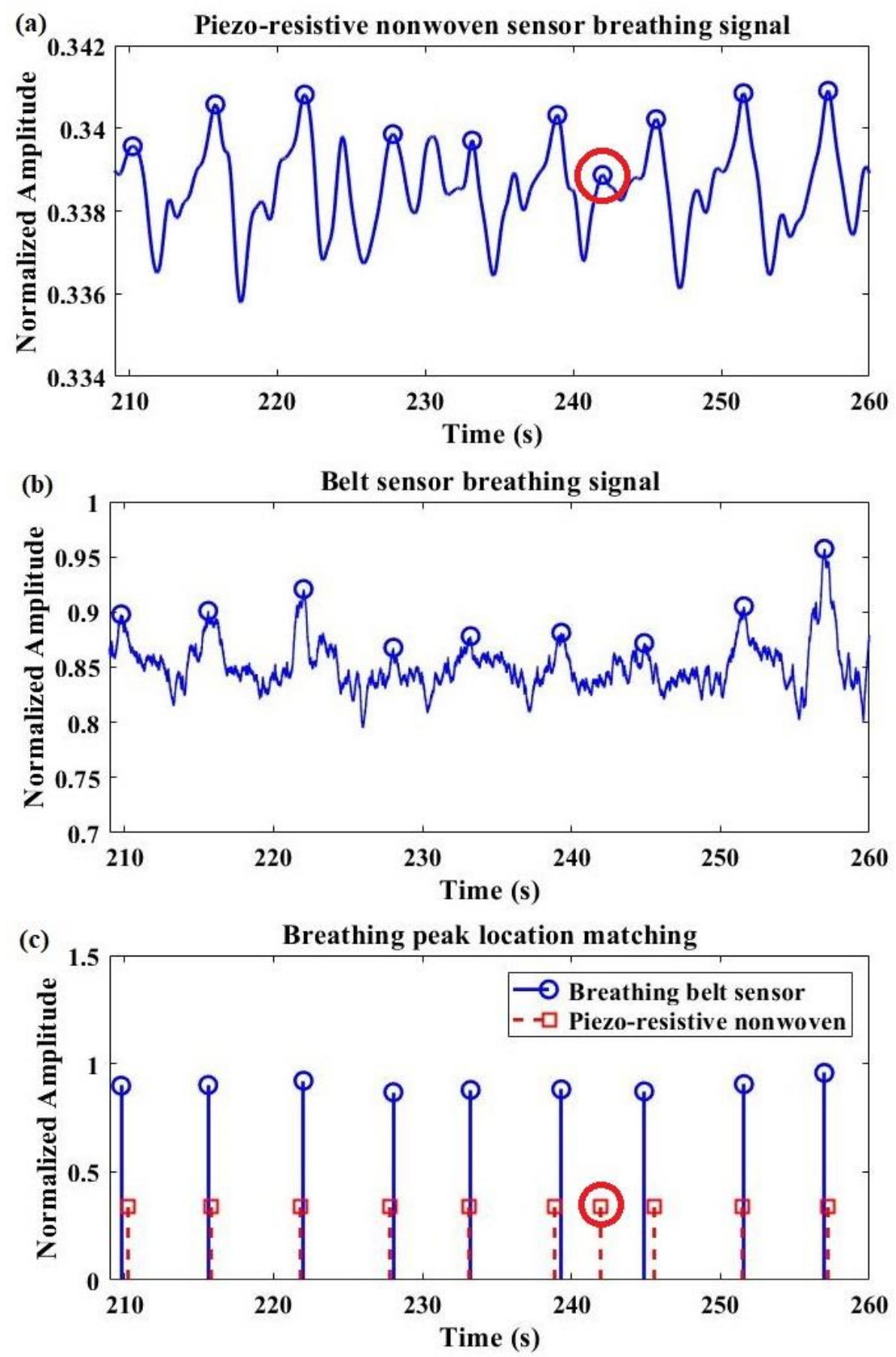

Figure 18. Breathing signal peak detection and location matching between the nonwoven piezo-resistive sensor and commercially available breathing belt sensor. (Marked: the false peaks detected).

Same as the heart signal acquisition, ten breathing signal tests were performed with the piezo-resistive nonwoven sensor and the breathing counts over one minute were determined. The statistical data in Table $\mathbf{6}$ show that there are only negligible differences 
between the two types of sensors in the aspect of capturing the breathing signals and a high accuracy of $97.39 \%$ was achieved.

Table 6. Breathing rate (number of breaths per minute) comparison

\begin{tabular}{lll}
\hline Test & Breathing belt sensor & Nonwoven piezo-resistive sensor \\
\hline 1 & 11.31 & 11.68 \\
2 & 11.35 & 11.35 \\
3 & 12.77 & 14.06 \\
4 & 11.14 & 14.00 \\
5 & 11.62 & 11.42 \\
6 & 13.17 & 12.37 \\
7 & 11.89 & 10.96 \\
8 & 12.44 & 11.81 \\
9 & 10.85 & 13.03 \\
10 & 12.21 & 11.25 \\
Average & 11.87 & 12.19 \\
Standard error & 0.24 & 0.36 \\
Accuracy & & $97.39 \%$ \\
\hline
\end{tabular}

\section{Conclusions}

The paper introduces a novel nano silver ink impregnated wearable piezo-resistive sensor, constructed by the authors, based on nano silver ink impregnated nonwoven fabric. This piezo-resistive sensor is fabricated by sandwiching the nano silver ink impregnated nonwoven fabric with two layers of silver knitted fabric, on either side of the nonwoven fabric, with the aid of silver impregnated webbing fabric. The research shows that the silver impregnated webbing fabric layers, which bind the nano silver ink impregnated nonwoven fabric, improve the electrical connection between the silver knitted fabric layers and the piezo-resistive nonwoven fabric layer. The use of the silver impregnated webbing fabric reduces the error bars of the sensor resistance in the experiments in the low pressure region, without sacrificing the sensitivity of the piezoresistive sensor. The wearable piezo-resistive sensors produced from the embossed dotted pattern nonwoven fabric and smooth surface nonwoven fabrics showed pressure sensitivities of $8.433 \Omega / \mathrm{kPa}$ and $1.865 \Omega / \mathrm{kPa}$, respectively, within the pressure range of 1 to $2 \mathrm{kPa}$. It was also found from the cyclic loading tests that the recoverability of the sensor from compression was critical to the reproducible piezo-resistive perform. Therefore, the nonwoven materials themselves already have an edge over other textile 
materials, where improvements can be made in respect of partial bonding in order to obtain better compressive recoverability.

The cardiorespiratory signal acquisition tests were carried out using these two types of piezo-resistive sensors. The experiments showed that both types of piezo-resistive sensors were capable of detecting the breathing signals during normal breathing, rapid breathing and during arm movement. Results prove that the piezo-resistive sensor made using the nonwoven fabric having a dotted surface pattern provides more reliable and stable cardiorespiratory signals, with a sensor accuracy of $92.83 \%$ and $97.39 \%$ for capturing heart signals and breathing signals, respectively. It is also found that, even though the signal amplitude from the piezo-resistive sensors were low, a piezo-resistive nonwoven sensor with an embossed dotted surface pattern perform was capable of capturing the complete breathing signal and the BCG signal. By comparing the recorded cardiorespiratory signals with that from the commercially available bio-signal monitoring device, within the sensor application pressure of 1 to $2 \mathrm{kPa}$, it can be seen that this new wearable piezo-resistive sensor technology is capable of being used in general cardiorespiratory monitoring applications.

\section{Funding}

This research did not receive any specific grant from funding agencies in the public, commercial, or not-for-profit sectors.

\section{References}

[1] C.L. Cooper, J. Marshall, Occupational Sources of Stress: A Review of the Literature Relating to Coronary Heart Disease and Mental Ill Health, in: C. Cooper (Ed.), From Stress to Wellbeing Vol. 1 Theory Res. Occup. Stress Wellbeing, 1st ed., Palgrave Macmillan UK, 2013: pp. 3-23. doi:10.1057/9781137310651.

[2] F.G. O'Connor, J.P. Kugler, R.G. Oriscello, Sudden death in young athletes: Screening for the needle in a haystack, Am. Acad. Fam. Physicians. 57 (1998) 2763-2770.

[3] S. Choi, Z. Jiang, A novel wearable sensor device with conductive fabric and PVDF film for monitoring cardiorespiratory signals, Sensors Actuators, A Phys. 128 (2006) 317-326. doi:10.1016/j.sna.2006.02.012.

[4] C. Bäckman, M. Kullander, Sweden: EWCO comparative analytical report on Work-related Stress, (2010). http://www.eurofound.europa.eu/observatories/eurwork/comparativeinformation/national-contributions/sweden/sweden-ewco-comparative-analyticalreport-on-work-related-stress (accessed January 26, 2017).

[5] G. Loriga, N. Taccini, D. De Rossi, R. Paradiso, Textile sensing interfaces for cardiopulmonary signs monitoring., Conf. Proc. IEEE Eng. Med. Biol. Soc. 7 (2005) 7349-52. doi:10.1109/IEMBS.2005.1616209.

[6] T. Linz, C. Kallmayer, R. Aschenbrenner, H. Reichl, Embroidering electrical interconnects with conductive yarn for the integration of flexible electronic modules into fabric, Proc. - Int. Symp. Wearable Comput. ISWC. 2005 (2005) 8689. doi:10.1109/ISWC.2005.19. 
[7] J.H. Son, D.H. Lee, Y.J. Cho, M.H. Lee, Very Thin Spin-Coated Silver Films via Transparent Silver Ink for Surface Plasmon Resonance Sensor Applications, 2012. doi:10.1166/jnn.2012.6352.

[8] N. Luo, W. Dai, C. Li, Z. Zhou, L. Lu, C.C.Y. Poon, S.C. Chen, Y. Zhang, N. Zhao, Flexible Piezoresistive Sensor Patch Enabling Ultralow Power Cuffless Blood Pressure Measurement, Adv. Funct. Mater. 26 (2016) 1178-1187. doi:10.1002/adfm.201504560.

[9] S.N. Nihtianov, G.C.M. Meijer, Application challenges of capacitive sensors with floating targets, IEEE AFRICON Conf. (2011) 13-15. doi:10.1109/AFRCON.2011.6072177.

[10] D. Du, P. Li, J. Ouyang, Graphene coated nonwoven fabrics as wearable sensors, J. Mater. Chem. C. 4 (2016) 3224-3230. doi:10.1039/C6TC00350H.

[11] H. Dai, E. Thostenson, T. Schumacher, Processing and Characterization of a Novel Distributed Strain Sensor Using Carbon Nanotube-Based Nonwoven Composites, Sensors. 15 (2015) 17728-17747. doi:10.3390/s150717728.

[12] Z.H. Liu, C.T. Pan, C.K. Yen, L.W. Lin, J.C. Huang, C.A. Ke, Crystallization and mechanical behavior of the ferroelectric polymer nonwoven fiber fabrics for highly durable wearable sensor applications, Appl. Surf. Sci. 346 (2015) 291-301. doi:10.1016/j.apsusc.2015.03.173.

[13] Z.H. Liu, C.T. Pan, L.W. Lin, J.C. Huang, Z.Y. Ou, Direct-write PVDF nonwoven fiber fabric energy harvesters via the hollow cylindrical near-field electrospinning process, Smart Mater. Struct. 23 (2014) 25003. doi:10.1088/09641726/23/2/025003.

[14] J.F. Pierson, E. Rolin, C. Clement-Gendarme, C. Petitjean, D. Horwat, Effect of the oxygen flow rate on the structure and the properties of $\mathrm{Ag}-\mathrm{Cu}-\mathrm{O}$ sputtered films deposited using a $\mathrm{Ag} / \mathrm{Cu}$ target with eutectic composition, Appl. Surf. Sci. 254 (2008) 6590-6594. doi:10.1016/j.apsusc.2008.04.026.

[15] A.L. Dearden, P.J. Smith, D.Y. Shin, N. Reis, B. Derby, P. O'Brien, A low curing temperature silver ink for use in ink-jet printing and subsequent production of conductive tracks, Macromol. Rapid Commun. 26 (2005) 315-318. doi:10.1002/marc.200400445.

[16] M.N. Martin, A.J. Allen, R.I. Maccuspie, V.A. Hackley, Dissolution, agglomerate morphology, and stability limits of protein-coated silver nanoparticles, Langmuir. 30 (2014) 11442-11452. doi:10.1021/la502973z.

[17] X.S. Shen, G.Z. Wang, X. Hong, W. Zhu, Nanospheres of silver nanoparticles: agglomeration, surface morphology control and application as SERS substrates, Phys. Chem. Chem. Phys. 11 (2009) 7450. doi:10.1039/b904712c.

[18] J. Felba, K. Nitsch, T. Piasecki, P. Paluch, a. Moscicki, a. Kinart, The influence of thermal process on electrical conductivity of microstructures: Made by ink-jet painting with the use of ink containing nano sized silver particles, 2009 9th IEEE Conf. Nanotechnol. 8 (2009) 408-411. 
[19] M.A.H. Khondoker, S.C. Mun, J. Kim, Synthesis and characterization of conductive silver ink for electrode printing on cellulose film, Appl. Phys. A Mater. Sci. Process. 112 (2013) 411-418. doi:10.1007/s00339-012-7419-z.

[20] W.W. Li, L.X. Mo, J.L. Fu, W.B. Li, J. Ran, X.M. Fan, Y.L. Li, L.H. Li, Fabrication of Transparent Conductive Film Using Water-Based Nano-Silver Gravure Ink, Key Eng. Mater. 562-565 (2013) 1440-1443. doi:10.4028/www.scientific.net/KEM.562-565.1440.

[21] J. Ran, L.X. Mo, W.B. Li, W.W. Li, X.M. Fan, J.L. Fu, L.H. Li, A Nano-Silver Inkjet Conductive Ink with Excellent Adhesion, Appl. Mech. Mater. 262 (2012) 501-504. doi:10.4028/www.scientific.net/AMM.262.501.

[22] W. Li, L. Mo, J. Fu, W. Li, J. Ran, X. Fan, Y. Li, L. Li, Preparation of Waterbased Nano-silver Gravure Conductive Ink Used for Printed Electronics, Adv. Print. Packag. Technol. 262 (2013) 523-526. doi:10.4028/www.scienfic.net/AMM.262.523.

[23] S.B. Walker, J.A. Lewis, Reactive Silver Inks for Patterning High-Conductivity Features at Mild Temperatures, J. Am. Chem. Soc. 134 (2012) 1419-1421. doi: $10.1021 / \mathrm{ja} 209267 \mathrm{c}$.

[24] R.D. Mancosu, Q. Quintero, J, A, R.E.S. Azevedo, Sintering, in Different Temperatures, of Traces of Silver Printed in Flexible Surfaces, in: 11th. Int. Conf. Therm. Mech. Multiphys Simul. Exp. Micro-Electronics Micro-Systems, EuroSimE 2010, Bordeaux, France, 2010: pp. 1-4.

[25] T. Falat, J. Felba, A. Moscicki, A. Smolarek, K. Bock, D. Bonfert, Influence of nano silver filler content on properties of ink-jet printed structures for microelectronics, Electron. Syst. Integr. Technol. Conf. ESTC 2010 - Proc. (2010) 5-9. doi:10.1109/ESTC.2010.5642899.

[26] C.F.J. Kuo, T.L. Su, C.P. Tsai, Optimization of the needle punching process for the nonwoven fabrics with multiple quality characteristics by grey-based Taguchi method, Fibers Polym. 8 (2007) 654-664. doi:10.1007/BF02876005.

[27] S. Ma, V. Bromberg, L. Liu, F.D. Egitto, P.R. Chiarot, T.J. Singler, Low temperature plasma sintering of silver nanoparticles, Appl. Surf. Sci. 293 (2014) 207-215. doi:10.1016/j.apsusc.2013.12.135.

[28] D. Tobjörk, H. Aarnio, P. Pulkkinen, R. Bollström, A. Määttänen, P. Ihalainen, T. Mäkelä, J. Peltonen, M. Toivakka, H. Tenhu, R. Österbacka, IR-sintering of ink-jet printed metal-nanoparticles on paper, Thin Solid Films. 520 (2012) 2949-2955. doi:10.1016/j.tsf.2011.10.017.

[29] B. Polzinger, F. Schoen, V. Matic, J. Keck, H. Willeck, W. Eberhardt, H. Kueck, UV-sintering of inkjet-printed conductive silver tracks, Proc. IEEE Conf. Nanotechnol. (2011) 201-204. doi:10.1109/NANO.2011.6144541.

[30] S. Magdassi, M. Grouchko, O. Berezin, A. Kamyshny, Triggering the sintering of silver nanoparticles at room temperature, ACS Nano. 4 (2010) 1943-1948. doi:10.1021/nn901868t. 
[31] M.L. Allen, M. Aronniemi, T. Mattila, A. Alastalo, K. Ojanperä, M. Suhonen, H. Seppä, Electrical sintering of nanoparticle structures, Nanotechnology. 19 (2008) 175201. doi:10.1088/0957-4484/19/17/175201.

[32] J. Perelaer, B.J. De Gans, U.S. Schubert, Ink-jet printing and microwave sintering of conductive silver tracks, Adv. Mater. 18 (2006) 2101-2104. doi:10.1002/adma.200502422.

[33] E.T. Thostenson, T.-W. Chou, Microwave processing: fundamentals and applications, Compos. Part A Appl. Sci. Manuf. 30 (1999) 1055-1071. doi:10.1016/S1359-835X(99)00020-2.

[34] D.K. Cheng, Field and wave electromagnetics, 2nd ed., Addison-Wesley, 1989.

[35] NI 9219 operating instructions and specifications, 2009.

[36] Z. Gao, Optimisation of size, shape and location of resistive knitted electro-textile electrodes for heart signal (ECG) sensing, The University of Manchester, 2015.

[37] R. Berkow, The Merck Manual of Medical Information, Merck, New Jersey, 1997.

[38] R. Renz, V. Alstädt, G.W. Ehrenstein, Hysteresis Measurements for Characterizing the Dynamic Fatigue of R-SMC, J. Reinf. Plast. Compos. 7 (1988) 413-434. doi:10.1177/073168448800700502.

[39] D.M. Ionel, M. Popescu, M.I. McGilp, T.J.E. Miller, S.J. Dellinger, R.J. Heideman, Computation of core losses in electrical machines using improved models for laminated steel, IEEE Trans. Ind. Appl. 43 (2007) 1554-1564. doi:10.1109/TIA.2007.908159.

[40] S. Elmarzougui, S. Ben Abdessalem, F. Sakli, Hysteresis measurement for characterising the dynamic fatigue of textile artificial ligaments, J. Text. Inst. 102 (2011) 109-113. doi:10.1080/00405000903525260. 